\title{
POLÍTICAS TURÍSTICAS Y URBANÍSTICAS EN TORNO AL PATRIMONIO CULTURAL EN LA COMARCA DE LOS PUEBLOS BLANCOS DE CÁDIZ: ANÁLISIS DE LOS CASOS DE OLVERA Y ZAHARA DE LA SIERRA
}

\author{
José David Albarrán Periáñez. \\ Universidad Complutense de Madrid
}

\section{RESUMEN}

La situación económica de las últimas décadas en las zonas agrarias españolas, la crisis de las actividades primarias o la excesiva confianza en el sector de los servicios han favorecido la búsqueda de nuevas fórmulas de generación de riqueza en los territorios rurales de España, relacionadas, en muchos casos, con la diversificación económica a través de la puesta en valor con fines turísticos de su patrimonio cultural, algo que a veces ha consagrado estos lugares como zonas usadas, consumidas y disfrutadas por unos individuos distintos a los residentes. En algunos casos este fenómeno, unido al desarrollo de políticas urbanísticas de crecimiento, ha propiciado procesos de museificación de las zonas urbanas históricas que han podido favorecer el abandono de las mismas por parte de la población residente, impulsado a su vez por el traslado de servicios, las restricciones por catalogación, etc. El método del análisis de casos permitió estudiar este fenómeno en dos municipios de la comarca de los Pueblos Blancos de la Sierra de Cádiz para establecer diferencias entre las políticas implementadas en este sentido y los resultados conseguidos, identificándose una serie de problemas relacionados con la falta de participación ciudadana y la escasez e inoperancia de las políticas de rehabilitación.

Palabras clave: Pueblos Blancos de Cádiz, gestión turística del patrimonio, gobernanza turística, realidad patrimonial, planificación turística local.

Recibido: 9 de febrero de 2016

Devuelto para su revisión: 30 de junio de 2016

Aceptado: 20 de octubre de 2016

Departamento de Geografía Humana. Universidad Complutense de Madrid. Ciudad Universitaria. Calle Profesor Aranguren, s/n. 28040 MADRID (España).E-mail: josedalb@ucm.es 


\title{
Tourism and urban policies around the cultural heritage in the region of the Pueblos Blancos of Cadiz: analysis of the cases of Olvera and Zahara de la Sierra
}

\begin{abstract}
The economic situation in the Spanish agricultural zones in the last thirty years and the economic crisis of the primary activities or the over-reliance of the services sector have contributed to new ways to increase income into rural areas of Spain. There are related to the diversification of their economies which has led to an increased value of the cultural heritage in order to promote tourism, something that sometimes has devoted these places as areas used, consumed and enjoyed by a few different individuals to residents. It has led in some cases to the development of a museification of urban historic areas, at the time that people are leaving these places, boosted by the removal of the services sector and restrictions in designated areas. The analytic method of cases allowed us to study this phenomenon in two different towns of the district called Pueblos Blancos de la Sierra de Cadiz to establish differences between the policies implemented in this regard and the results obtained. We have deduced a number of problems related to the lack of citizen participation and the shortage and the ineffectiveness of rehabilitation policies.
\end{abstract}

Keywords: White Towns of Cadiz, heritage tourism management, tourism governance, actually heritage, local tourism planning.

\section{INTRODUCCIÓN}

Con la entrada de España en la Comunidad Económica Europea, las regiones españolas se convirtieron en beneficiarias de una serie de fondos a través de los que se ha buscado corregir los desequilibrios entre zonas rurales y urbanas, así como conseguir mejoras en las condiciones socioeconómicas de los habitantes de las mismas. Por medio de programas como LEADER, PRODER o URBAN ${ }^{1}$, financiadores de iniciativas para la diversificación económica de distintas áreas geográficas, se han llevado a cabo acciones que, en un buen número de casos, han estado regidas por medio de políticas de naturaleza turística y de conservación patrimonial.

La crisis del modelo de desarrollo seguido por los sistemas económicos vigentes, la generalización de una conciencia ambientalista o el surgimiento de una mentalidad interesada en la cultura y la calidad de vida, han favorecido en las últimas décadas del siglo XX una renovación hacia nuevos modelos de desarrollo que priman el uso sostenible de los recursos y pretenden resultados más allá del corto plazo. Esta conjunción de fenómenos económicos y sociales ${ }^{2}$ ha dado inicio a un proceso de revalorización de lo antiguo y una

1 Éste último en el caso de núcleos urbanos con dos programas operacionales: URBAN I (1994-1999) y URBAN II (2000-2006). En el primero de ellos se vieron beneficiadas 31 ciudades, mientras que en el segundo fueron 10 .

2 El detrimento de las actividades económicas primarias; la consolidación de España como destino turístico mundial con el alcance de la etapa de madurez y la necesidad de una reinvención del producto; una quizá excesiva confianza en el sector de los servicios y más concretamente en el turismo como fórmula mágica para aliviar la fractura económica y hacer frente al problema social del paro, etc. 
apuesta por parte de las administraciones públicas por la recuperación, revalorización y consideración de los bienes patrimoniales como recursos de atracción de visitantes, extendiendo socialmente la unión de patrimonio y turismo iniciada por las élites culturales del siglo XVIII.

Con el objeto de garantizar la eficiencia de estas inversiones, a lo largo de las últimas décadas, surgen iniciativas regionales como el Plan General de Turismo Sostenible de la Junta de Andalucía, que proponen el uso óptimo de los recursos bajo el paraguas de la sostenibilidad. Así muchos organismos han desarrollado estrategias que se han dispuesto en torno a la idea de incentivar el crecimiento de un sector, el turístico, casi inexistente en las comarcas geográficas interiores, focalizando una considerable fracción de fondos europeos en iniciativas relacionadas con los segmentos turísticos rural, cultural o natural. El patrimonio se ha convertido en una herramienta básica en los modelos de planificación territorial a través de formas de gestión de muy diferente naturaleza, teniendo la capacidad de mercantilizar la cultura a través de los bienes patrimoniales, transformándolos en producto (Hernández, 2015), rentabilizando así recursos ya existentes en el territorio a través de los cambios en los usos de los mismos. Su recuperación como motor de la actividad turística se ha caracterizado en las últimas décadas por la obtención de unos beneficios para la sociedad local no sólo de tipo económico, sino que además ha reportado importantes ejemplos de comunidades que han desarrollado una identidad colectiva en torno al mismo.

El sector del turismo ha sido así considerado una vía idónea para potenciar la diversificación económica de los territorios afectados por el declive de las actividades económicas primarias o industriales. Su importancia queda reflejada en los datos de la Organización Mundial del Turismo, según la cual un $37 \%$ de los viajes que se realizan en el mundo tienen por motivación principal el encuentro con la diferencia cultural a través del patrimonio (Troitiño, 2009). La Conferencia Mundial sobre Turismo y Cultura organizada por la OMT y la UNESCO en el mes de febrero de 2015 en Camboya deja entrever la importancia internacional que ha adquirido en los últimos años la necesidad de promover nexos de unión entre turismo y cultura.

La gestión turística en torno al patrimonio cultural que se desprende de este nuevo modelo de desarrollo ha sido definida por multitud de autores a lo largo de los últimos años, coincidiendo muchos de ellos en hacer alusión a una implementación de conocimientos específicos con el fin de otorgar uso turístico a aquellos bienes que conforman el patrimonio cultural (Fernández \& Guzmán, 2004; Velasco, 2009); pero esa no es tarea fácil debido a que los principios, valores y referencias de ambos sectores son muy diferentes entre sí, así como los actores implicados en ellos, las actividades que se desarrollan en torno a los mismos o el fin que persiguen. Igualmente, la rápida evolución que se está produciendo en ambos casos y la visión que la ciudadanía tiene de los mismos influye en las posibles reticencias que pueden existir para la colaboración entre los dos sectores (Velasco, 2009).

Un estudio del Sistema Turístico Local ayuda a entender la relación entre el desarrollo turístico de un determinado territorio y los nexos entre los actores implicados, generalmente del mismo territorio (Oliveira, Pasquotto \& Morales, 2014), así como los vínculos entre este sector y otro tipo de políticas. Uno de los problemas más comunes que se identifican en la gestión de las políticas urbanísticas, patrimoniales y turísticas de 
núcleos urbanos de cierta relevancia monumental es el de la museificación, un concepto patente en muchos territorios cuya organización urbana ha sucumbido a los gustos ideales del turismo potencial, en favor de una escenografía propia del gusto romántico y característica de lo preestablecido. Así, muchos proyectos llevados a la práctica en localidades andaluzas, mayoritariamente pegadas al litoral mediterráneo, han propiciado un desarrollo favorecedor de espacios del gusto del turista, conservando aquellos bienes patrimoniales alabados por éstos y prefiriendo situar en estos espacios, normalmente los centros históricos, servicios enfocados al visitante, relegando muchas veces fuera de sus márgenes la vida corriente de la ciudadanía local.

Este paulatino abandono de las zonas históricas por parte de la población autóctona, síntoma de los procesos de museificación, está condicionado por factores complejos de gestión de los recursos por parte de los agentes implicados en la gobernanza municipal. Una fisonomía urbana complicada heredada de una tradicionalidad como emplazamiento defensivo, el uso extendido del coche, o la implementación de políticas centradas en la expansión constructiva... han posibilitado que en las últimas décadas muchos cascos históricos hayan asistido a un proceso de abandono. Estas causas se han visto enfatizadas por una creciente especialización turística en núcleos de población más reducidos que han dirigido su desarrollo económico a un sector en auge. La cuestión radica entonces en cómo concebir un desarrollo capaz de conciliar los usos tradicionales del espacio con el turismo. Éste debe ser, por tanto, un elemento cuya presencia en el territorio motive la reactivación de la tradición y la consolidación del patrimonio (Prats y Santana, 2011), constituyéndose como un instrumento de desarrollo económico, social y cultural.

\section{HIPÓTESIS}

La investigación que centra el presente artículo persiguió responder a la hipótesis de que las políticas turísticas implementadas, junto a las urbanísticas y patrimoniales, pueden ser una de las causas de la pérdida de valor social de los cascos históricos en los núcleos urbanos de la Sierra de Cádiz. Éstas, desarrolladas en áreas rurales de cierta envergadura patrimonial, pueden constituir importantes frenos al desarrollo si no conciben a los elementos patrimoniales dentro de las dinámicas sociales de estos espacios.

\section{OBJETIVOS}

Apreciando la existencia de un proceso de abandono poblacional de las zonas históricas de los núcleos que se estudiaron, se establecieron los siguientes objetivos generales con objeto de dar respuesta a la hipótesis planteada:

a. Determinar cuáles han sido los procesos que han propiciado la presente situación de marginación del patrimonio cultural en determinados municipios de la comarca de los Pueblos Blancos de la Sierra de Cádiz.

b. Analizar las políticas que han favorecido el despoblamiento progresivo del casco histórico en dos localidades con características socioeconómicas, históricas y políticas diferentes, llevadas a cabo en las últimas décadas. 
c. Definir los principales actores sociales que han intervenido en la protección, así como en la gestión turística del patrimonio, analizando sus discursos y acciones en ambas localidades.

d. Conocer cuáles han sido las principales medidas gubernamentales para la gestión del patrimonio cultural de la zona, su vinculación con la explotación turística, así como los resultados de las mismas.

\section{METODOLOGÍA}

El método del análisis de casos permite inquirir de manera detallada en un tema con mayor profundidad que los estudios estadísticos (Beck, 2010; Yacuzzi, 2005), suponiendo una herramienta de obtención de conocimiento más preciso sobre cualquier tema u objeto. Los estudios de caso otorgan prioridad al conocimiento profundo del caso y sus particularidades, definido éste como un sistema delimitado en tiempo y espacio de actores y relaciones entre ellos, a través de una recolección de información orientada a describir la complejidad de las causalidades locales (Neiman y Quaranta, 2006). Permite combinar procedimientos cuantitativos y cualitativos (Meyer, 2001), y cuando este tipo de estudios se basa en varios ejemplos, el análisis empírico atiende a la comparación para determinar resultados.

Bajo el marco teórico de la gobernanza y el patrimonio, y de acuerdo con la sistemática propia de este tipo de trabajos basados en el análisis etnográfico a través de estudios de casos de Olvera y Zahara, se abordó una metodología fundamentada en cuatro fases complementarias:

a. Estudio de la realidad actual de ambas localidades a través de bibliografía específica y material documental.

b. Trabajo de campo con entrevistas a agentes implicados en la gestión turística y patrimonial de ambas localidades.

c. Análisis de los discursos y relaciones entre agentes implicados.

d. Redacción de estrategias específicas.

a. Apelación a fuentes bibliográficas y documentales para dar sentido a un estudio sobre el pasado de una sociedad concreta. Esto supuso un primer análisis en profundidad a través de publicaciones, libros y herramientas tales como ortofotografías, sistemas de información geográfica o archivos fotográficos. Fue imprescindible en esta etapa el análisis de la documentación institucional pública de las distintas administraciones locales ${ }^{3}$, con las actas plenarias como herramienta básica a partir

3 Actas de plenos ordinarios y extraordinarios que tuvieran lugar entre el mes de abril de 1979 y la fecha en que se desarrolló el proceso de estudio bibliográfico entre los meses de diciembre de 2014 y abril de 2015; Publicaciones editadas por ambos consistorios basadas en temas relacionados con el turismo, el patrimonio y la cultura con incidencia en su término municipal durante las últimas décadas; Revistas locales, de periodicidad anual o de carácter extraordinario; Trabajos de divulgación editados por el Servicio de Publicaciones de la Diputación de Cádiz sobre prospecciones e intervenciones arqueológicas en ambos municipios; Trabajos de investigación que toman como protagonista de alguno u otro modo a la comarca en cuestión; Planes territoriales y de bienes culturales de la Junta de Andalucía; etcétera. 
de las cuales estudiar las diferentes medidas gubernamentales llevadas a cabo en las últimas décadas en torno al urbanismo, el turismo y el patrimonio local. Este proceso conllevó la consecución de unas fichas informativas de cada uno de los municipios, donde se recogen, organizados por legislaturas políticas, los hechos más significados acaecidos en materia de patrimonio y turismo en estos territorios, acciones gubernamentales e iniciativas de agentes no políticos ordenados cronológicamente y según materia con objeto de configurar un esquema de análisis que permitiera identificar a los distintos actores implicados en la gestión turística y patrimonial local y los nexos de unión entre ellos (Anexo I).

b. Una vez finalizada la fase de análisis documental, que supuso un interesante proceso de familiarización con el entorno y aproximación a su realidad patrimonial, comenzó un segundo proceso metodológico que pasó por la realización de entrevistas en profundidad a los más importantes agentes locales implicados en la problemática que se analizaba, a través de la creación de diferentes cuestionarios (Gobernantes, Opositores y Agentes No Políticos), estructurados en tres grandes bloques temporales (Pasado, Presente y Futuro) a la vez subdivididos en apartados que respondían a las siguientes temáticas: 1. Puesta en valor del patrimonio cultural y su protección, 2. Actuaciones llevadas a cabo en materia patrimonial, 3. Actuaciones llevadas a cabo en materia turística y 4. Relaciones entre actores. Se desarrolló un proceso de recogida de datos a través de grabaciones que fueron transcritas posteriormente, a fin de organizar la información proporcionada por estos actores durante las audiencias. Fueron entrevistados un total de 14 agentes implicados en el municipio de Olvera y 12 agentes en Zahara de la Sierra, en su mayoría políticos locales, algunos con cargos supramunicipiales -activos en la actualidad o no-, técnicos, miembros de colectivos empresariales del sector turístico y asociaciones, cronistas oficiales, párrocos y antropólogos con trabajos de incidencia en la zona.

c. Estos cuestionarios sirvieron para conocer los diversos discursos existentes en torno a la problemática analizada, las relaciones que se establecían entre los agentes y la incidencia que éstas tenían y habían tenido en el desarrollo social y económico local.

d. La última fase radicó en un estudio propositivo. Se desarrolló un proceso de identificación de problemas y oportunidades que desembocó en la redacción de una serie de conclusiones y propuestas de mejora a nivel comarcal e individual para los municipios analizados en el estudio, que fueron plasmadas en el trabajo La gestión turística del patrimonio cultural en la comarca de los Pueblos Blancos de la Sierra de Cádiz: análisis de casos.

\section{CARACTERIZACIÓN BÁSICA DE LA COMARCA DE LOS PUEBLOS BLANCOS}

Al norte de la provincia gaditana, la comarca de la Sierra de Cádiz, conglomerado rural con una superficie de 194.900 hectáreas alrededor del Parque Natural de la Sierra de Grazalema, se perfila como uno de los entornos más característicos de la tradición 


\section{Figura 1 \\ REPRESENTACIÓN GRÁFICA DE LA SITUACIÓN GEOGRÁFICA DE LA COMARCA DE LA SIERRA DE CÁDIZ}

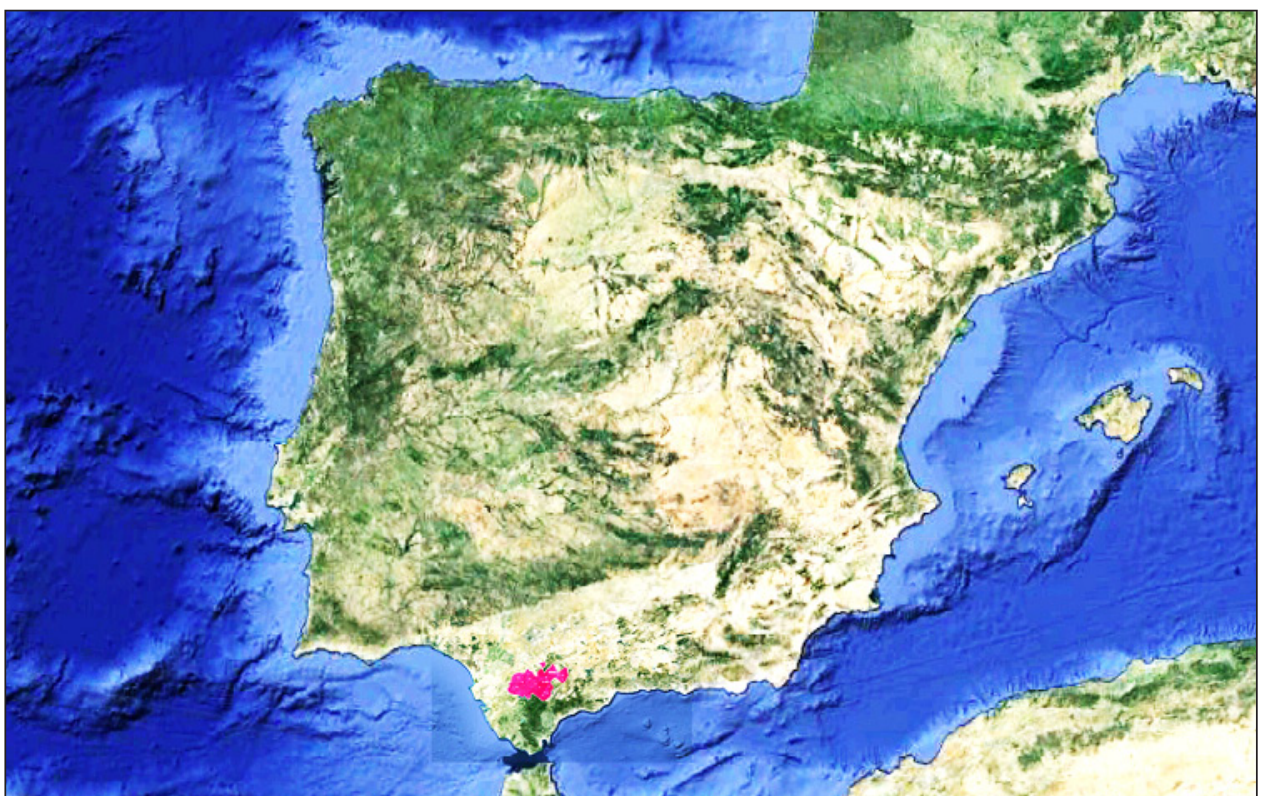

Fuente: elaboración propia a partir de cartografía para Google Earth.

andaluza, con diferentes ejemplos de modelos de gestión patrimonial municipal. Los distintos municipios que componen la región, con un total de 118.015 habitantes ${ }^{4}$, han desarrollado durante las últimas décadas políticas muy diversas dirigidas a la conservación de su patrimonio cultural, el desarrollo urbanístico y la sostenibilidad de sus recursos. De esta forma existen valiosos ejemplos de cómo ha sido el devenir posterior de esas medidas y sus repercusiones en la población local, que, en gran medida, ha experimentado un proceso de abandono de los cascos históricos, alejándose de los elementos patrimoniales. Esta huída de las zonas históricas se ha visto favorecida por el traslado de los servicios hacia áreas de expansión urbana, con la consecuente puesta a disposición de los visitantes de un escenario pintoresco vacío, presidido por los bienes monumentales más importantes de estas poblaciones. Por otro lado, desde hace décadas, existen voces que denuncian la pérdida significativa de patrimonio arquitectónico y etnológico sufrida por la comarca en un afán modernizador bajo un discurso popular meramente monumentalista (Moreno, 1983; Castellano, 2012).

4 Dato que representa el 9,5\% de la población provincial, una cifra que supone casi la mitad que en 1857, donde 14 de los 19 municipios que en la actualidad componen la comarca suponían un porcentaje del 12,9\%. De lo que se desprende un claro desfase en los ritmos de crecimiento demográfico de la Sierra y la Provincia respectivamente (Suárez, 1982). Instituto Nacional de Estadísticas (INE), datos del año 2015. 
Andalucía es uno de los principales destinos turísticos de España ${ }^{5}$, el sector supone alrededor del 12,9\% del PIB de la Comunidad ${ }^{6}$, y en su Plan de Ordenación del Territorio ${ }^{7}$ se da especial importancia a la comarca serrana de los Pueblos Blancos, con numerosas declaraciones de Conjunto Histórico-Artístico, enmarcada dentro de la Ruta del Legado Andalusí ${ }^{8}$ y próxima a varias ciudades patrimoniales reconocidas a nivel internacional como Ronda o Jerez. Hecho que, sin embargo, no se ve reflejado en el desarrollo turístico de la comarca, caracterizado por una escasa oferta en establecimientos turísticos. Como puede apreciarse en la Tabla 1, los diecinueve municipios que la conforman son, por lo general, los de menor capacidad alojativa de la provincia, exceptuando los casos de Arcos de la Frontera, Grazalema y El Bosque, tres municipios que aglutinan el 56,05\% del total de plazas de la comarca.

Las cifras de alojamiento en la Sierra de Cádiz representan el 19,53\% del número total de establecimientos en la provincia, sin embargo el reducido tamaño de los mismos hace que sólo el 7,16\% de las plazas se sitúen en la comarca. La especialización turística es escasa, lo que se traduce en la existencia de únicamente 4,77 plazas de alojamiento por cada 100 habitantes. Una cifra no excesivamente baja si se compara con el índice autonómico, que sitúa en 5,40 las plazas existentes por cada residente en la Comunidad, pero que no obstante resulta muy reducida si es comparada con otras comarcas rurales españolas, montañosas y de interior, como el Valle del Tiétar, en Ávila, con 12,55 plazas ${ }^{9}$, la comarca de la Cuadrilla de Añana, en la montaña alavesa, con 12,39 plazas de alojamiento por cada 100 habitantes $^{10}$, o el Valle de la Rioja Alta, con 21,65 plazas por cada 100 habitantes ${ }^{11}$, las dos últimas a menos de 80 kilómetros del litoral.

Uno de los principales problemas dentro del ámbito turístico comarcal que actualmente presentan estos municipios es el de ser lugares de paso, donde el número de pernoctaciones es muy reducido. Estos municipios se han convertido en motivo de excursiones cortas, realizadas desde otros núcleos turísticos de mayor relevancia, con duraciones inferiores a un día, en las que a lo sumo se visitan dos pueblos, los más cercanos al lugar de origen, y en las que apenas se produce gasto económico. Municipios como Grazalema parten desde el reconocimiento de su nombre debido al parque natural homónimo, y otros como Setenil de las Bodegas y Arcos de la Frontera se valen de su cercanía a núcleos urbanos de gran notoriedad turística como Ronda o Jerez de la Frontera. Así, sólo un 6,15\% de las pernoctaciones que se realizan en la provincia gaditana se producen en alguno de los diecinueve municipios de la comarca, suponiendo ésta el 26,69\% de la superficie total provincial. Comparando estas cifras con las arrojadas por la tabla anterior en cuanto a la proporción de plazas se deduce la existencia de un tejido turístico empresarial muy ajustado a la demanda.

5 Andalucía ocupaba el cuarto puesto tras la Comunidad de Madrid, País Vasco y Cataluña en cuanto al índice que rige la competitividad turística de los destinos en el año 2010, según el indicador Monitur de Exceltur.

6 Portal web de la Junta de Andalucía.

7 Plan de Ordenación del Territorio de Andalucía (POTA), en vigor desde el 30 de diciembre de 2007.

8 Conjunto de ocho caminos históricos que recorren más de 200 localidades de Andalucía, gestionados por una Fundación de la Junta de Andalucía, participada por la Consejería de Turismo y Comercio, la Consejería de Educación, Cultura y Deporte y la Consejería de Presidencia.

9 García y De La Calle, 2006.

10 Eustat (Instituto Vasco de Estadística), Indicadores de Sostenibilidad, San Sebastián, 2010.

11 Instituto de Estadística de La Rioja, Estadísticas Económicas, Logroño, 2016. 


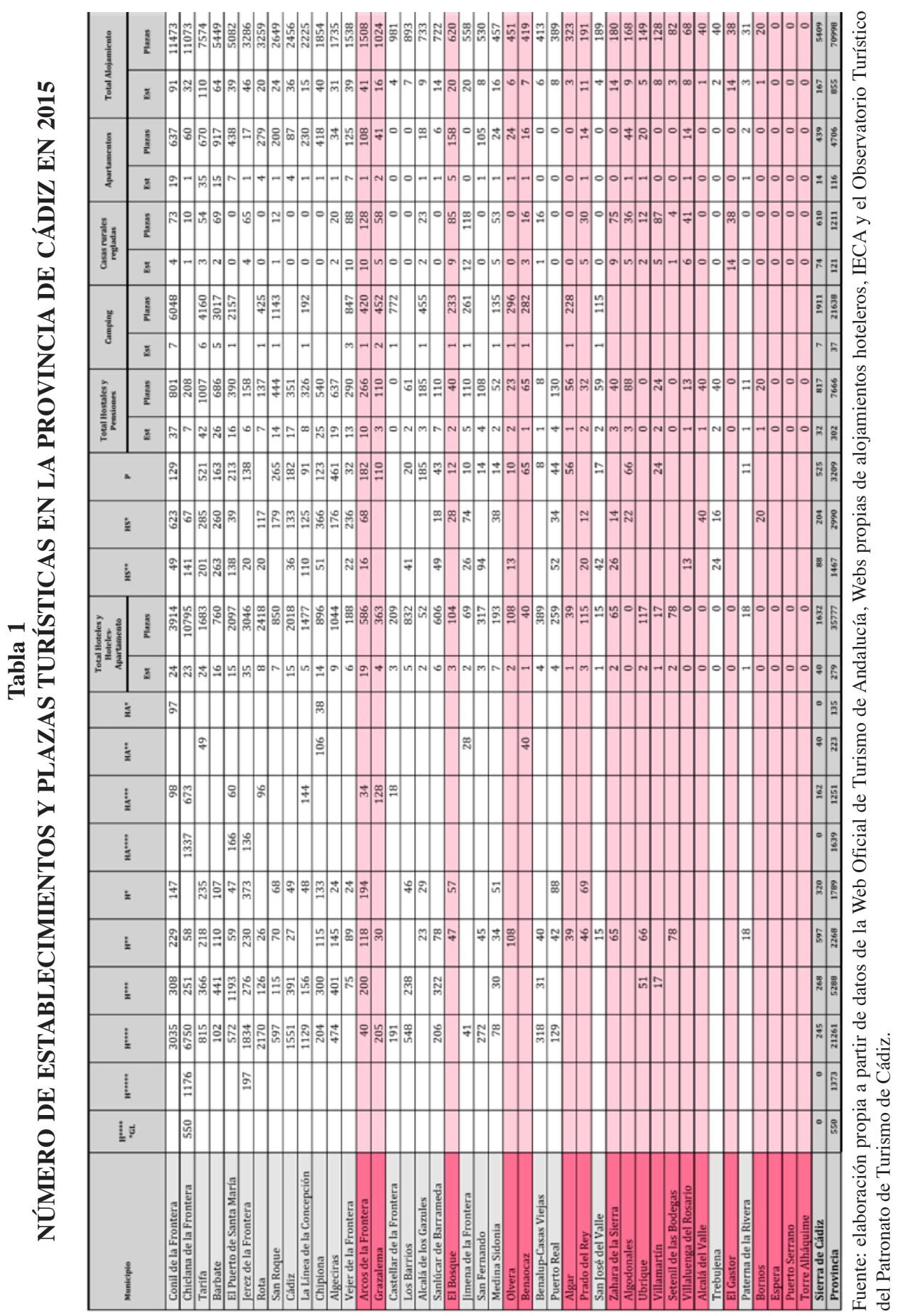

Cuadernos de Turismo, 40, (2017), 13-43 
Tabla 2

ESTIMACIÓN DE VIAJEROS Y PERNOCTACIONES EN LA PROVINCIA EN 2015

\begin{tabular}{|c|c|c|c|c|c|}
\hline & \multicolumn{2}{|c|}{ Viajeros } & \multicolumn{3}{|c|}{ Pernoctaciones } \\
\hline & Totales & $\begin{array}{l}\text { Porcentaje } \\
\text { que } \\
\text { representa }\end{array}$ & Totales & $\begin{array}{l}\text { Porcentaje } \\
\text { que } \\
\text { representa }\end{array}$ & $\begin{array}{l}\text { Noches por } \\
\text { turista }\end{array}$ \\
\hline Costa de la Luz & 1.823 .077 & 74,50 & 5.888 .534 & 80,54 & 3,23 \\
\hline Jerez de la Frontera & 282.358 & 11,54 & 619.432 & 8,47 & 2,19 \\
\hline Zona de Campiña & 191.115 & 7,81 & 354.247 & 4,84 & 1,85 \\
\hline Sierra de Cádiz & 150.393 & 6,15 & 449.384 & 6,15 & 2,99 \\
\hline Total provincial & 2.446 .943 & 100 & 7.311 .597 & 100 & 2,99 \\
\hline
\end{tabular}

Fuente: elaboración propia a partir de datos del INE e IECA para 2015.

Se presenta aquí un estudio a través de diferentes modelos de gestión local, que toman al patrimonio como motor de desarrollo económico y social a través del uso turístico del mismo, en mayor o menor medida. Un análisis de casos con ejemplos destacados de municipios de morfologías similares donde se han desarrollado modelos de gestión desigual, haciendo frente a realidades complejas en un periodo temporal que va de 1979 hasta la actualidad, coincidiendo con la implantación de los Ayuntamientos Democráticos en España.

\section{RECORRIDO POR LAS POLÍTICAS URBANÍSTICAS, TURÍSTICAS Y PATRIMONIALES EN OLVERA Y ZAHARA DE LA SIERRA, Y ANÁLISIS DE LOS DISCURSOS SOCIALES SOBRE LAS MISMAS}

A continuación se presentan los casos de dos municipios distintivos de la comarca de la Sierra de Cádiz, Olvera y Zahara de la Sierra, con una orografía similar, emplazados en cumbres sobre crestones de roca caliza (Suárez, 1982), y con características históricas, demográficas y socioeconómicas diferentes, donde ha comenzado a desarrollarse un progresivo abandono de los cascos históricos por parte de la población autóctona y una trasformación de su economía tradicionalmente arraigada al sector primario.

\section{Tabla 3 \\ DATOS DEMOGRÁFICOS Y TURÍSTICOS BÁSICOS DE LOS CASOS DE ESTUDIO}

\begin{tabular}{|l|c|c|c|c|}
\hline & $\begin{array}{c}\text { Población } \\
(\mathbf{2 0 1 5})^{\mathbf{a}}\end{array}$ & $\begin{array}{c}\text { Bienes Patrimoniales } \\
\text { Catalogados como BIC }\end{array}$ & $\begin{array}{c}\text { Plazas de } \\
\text { Alojamiento (2015) }^{\mathbf{c}}\end{array}$ & $\begin{array}{c}\text { Actores } \\
\text { entrevistados }\end{array}$ \\
\hline Olvera & 8.289 & 5 & 451 & 14 \\
\hline Zahara de la Sierra & 1.436 & 3 & 180 & 12 \\
\hline
\end{tabular}

Fuentes: a. Instituto Nacional de Estadística b. Catálogo General del Patrimonio Histórico Andaluz c. Elaboración propia a partir de datos de la Web Oficial de Turismo de Andalucía, Webs propias de alojamientos hoteleros, IECA y el Observatorio Turístico del Patronato de Turismo de Cádiz 


\subsection{Transformaciones urbanísticas}

Durante las décadas de 1970 y 1980, en plena transición política, comienzan a plantearse políticas de recuperación urbana a nivel local en las grandes ciudades españolas, que se rigen sobre todo por la redacción de planeamientos urbanísticos, la rehabilitación de viviendas y las políticas de patrimonio histórico (Troitiño, 2003). La visión monumentalista de la época y los deseos de cambio se ven reflejados en los procesos urbanos durante estos años.

\subsubsection{Olvera}

La localidad de Olvera ha sufrido una serie de cambios urbanísticos significativos durante el último medio siglo. La forma de afrontar los procesos de cambio por parte de los distintos agentes ha repercutido en gran medida en el desarrollo urbanístico y social, así como en la manera de gestionar el vasto patrimonio cultural de la localidad.

\section{Figura 2}

\section{OLVERA: ORTOFOTO 1956-57}

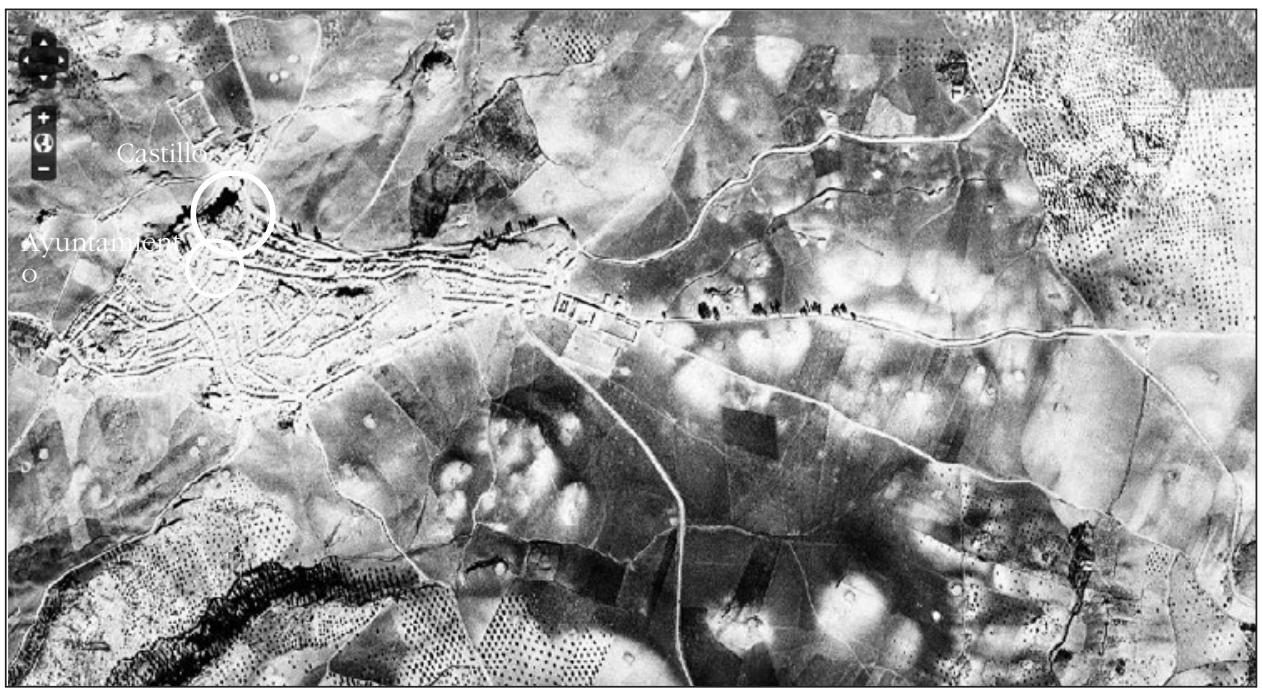

Fuente: Adaptación a partir del Comparador WMS Ortofotos, Canal Rediam, Consejería de Medio Ambiente y Ordenación del Territorio de la Junta de Andalucía.

A mediados de la década de 1950 el área que ocupaba el casco urbano olvereño presentaba una fisionomía que había perdurado durante décadas, con edificaciones de tamaño reducido y poca ornamentación exterior. Con los últimos años de la Dictadura Franquista y la transición a la Democracia Política, el municipio de Olvera, al igual que muchos otros españoles, experimentó una serie de cambios urbanísticos con la búsqueda de nuevos cánones arquitectónicos que modificaron considerablemente la imagen general 
de la localidad ${ }^{12}$ a la vez que se producía un primer desarrollo de viviendas hacia el Este en busca de zonas más cómodas en terrenos más llanos. A finales de la década de 1990 el ensanche llegaba a ocupar casi la misma superficie que el Conjunto Histórico-Artístico, declarado en $1983^{13}$. Con esta declaración, así como las de Bienes de Interés Cultural del Castillo, la Muralla urbana y el Castillo de Vallehermoso ${ }^{14}$, comenzaron a estructurarse herramientas de protección que fueron acompañadas de la redacción de las Normas Subsidiarias y diferentes planes urbanísticos parciales ${ }^{15}$.

\section{Figura 3 \\ CALLE CALZADA E IGLESIA PARROQUIAL DE NUESTRA SEÑORA DE LA ENCARNACIÓN EN 1906 Y EN 2012}

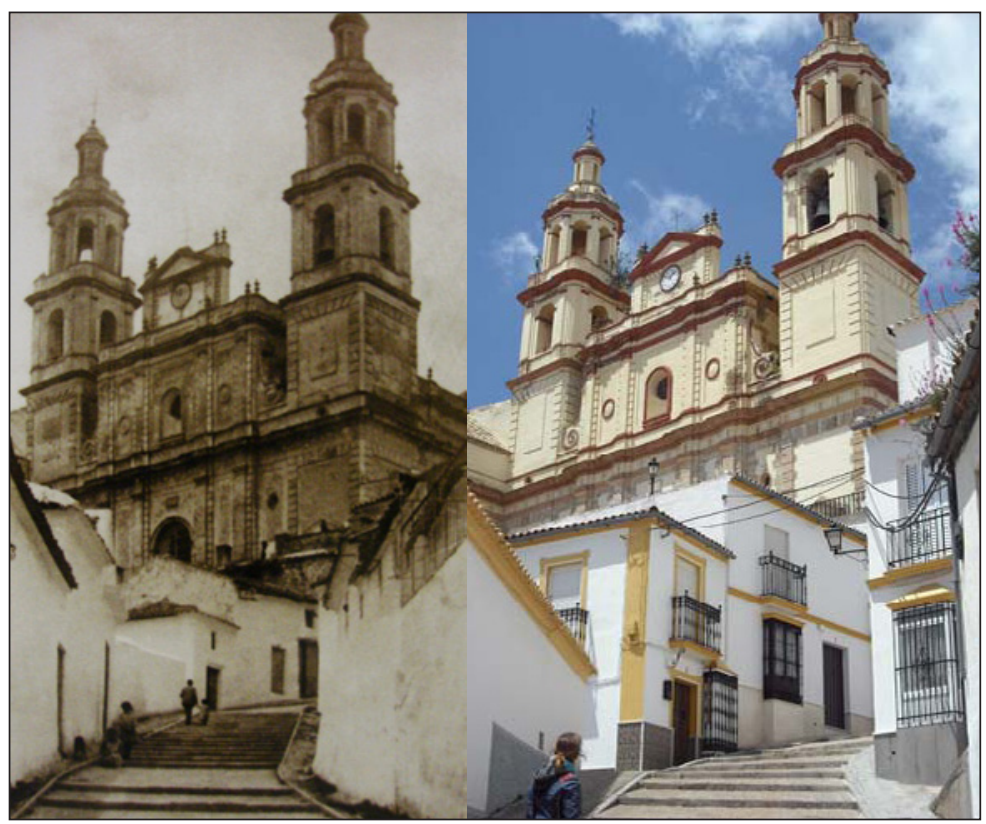

Fuente: Pedro Rodríguez Palma y Antonio Andrades.

12 Los primeros años de la transición supusieron una búsqueda de cánones arquitectónicos más próximos a los de las grandes urbes andaluzas, con ejemplos en la construcción de edificios de varias plantas en las calles principales, como los inmuebles situados en calle Jesús y calle Alfonso XI, dados de alta catastralmente en 1975 y 1976 respectivamente.

13 Inscrito en el Catálogo General del Patrimonio Histórico de Andalucía, con una superficie aproximada de 31 ha.

14 Inscritos en el Catálogo General del Patrimonio Histórico de Andalucía.

15 En 1984 se produce la elaboración, aprobación y puesta en práctica de las normas subsidiarias y de algunos planes parciales que atienden a propuestas de ubicación y tamaño del suelo urbanizable y propuesta de política urbana en el barrio de La Villa (el más antiguo de la localidad y donde se concentran los principales bienes monumentales) y, previa resolución de la Dirección General de Bellas Artes, a la restauración del Castillo y murallas que rodean al recinto, así como una protección especial de la zona declarada Conjunto Histórico Artístico. 
La búsqueda de una mayor calidad de vida de la comunidad local ha hecho que los cánones tradicionales de los inmuebles residenciales hayan sido desplazados por una arquitectura de espacios amplios y huecos más grandes. Aunque mayoritariamente se ha optado por la nueva construcción, en el ensanche, también han sido erigidas nuevas casas dentro del Conjunto Histórico-Artístico que han venido a sustituir a las existentes. La tendencia cooperativista en la industria olvereña ha favorecido también la proliferación de nuevos espacios laborales para actividades que, por sus características, no pueden desarrollarse en inmuebles tradicionales, así la creación y ampliación de un polígono industrial en el ensanche ha tenido una importancia considerable en el moderno trazado urbano olvereño.

La localidad se ha adaptado al automóvil, primándolo, y prefiriendo que sea la zona de ensanche la que concentre el mayor número de servicios y en torno a la cual gire la vida olvereña. Durante los últimos años se ha acentuado la compra de inmuebles de trazado antiguo en el casco histórico por parte de extranjeros, que prefieren respetar su estética, siendo ellos, en gran medida, los protagonistas de la defensa del patrimonio arquitectónico doméstico de la zona.

Es preciso señalar la poca correspondencia existente entre el fenómeno de crecimiento de la superficie urbana y la evolución demográfica de Olvera en el mismo periodo, pues la población censada en el municipio ha ido descendiendo paulatinamente. Ejemplo de ello es el fenómeno de las migraciones transnacionales en los setenta de una población que no puede ser retenida por la actividad rural (Suárez, 1982), o la primera década de los 2000, que se traducen en un abandono masivo de la población hacia zonas de mayor desarrollo económico.

\section{Figura 4 \\ OLVERA: ORTOFOTO 2010-11}

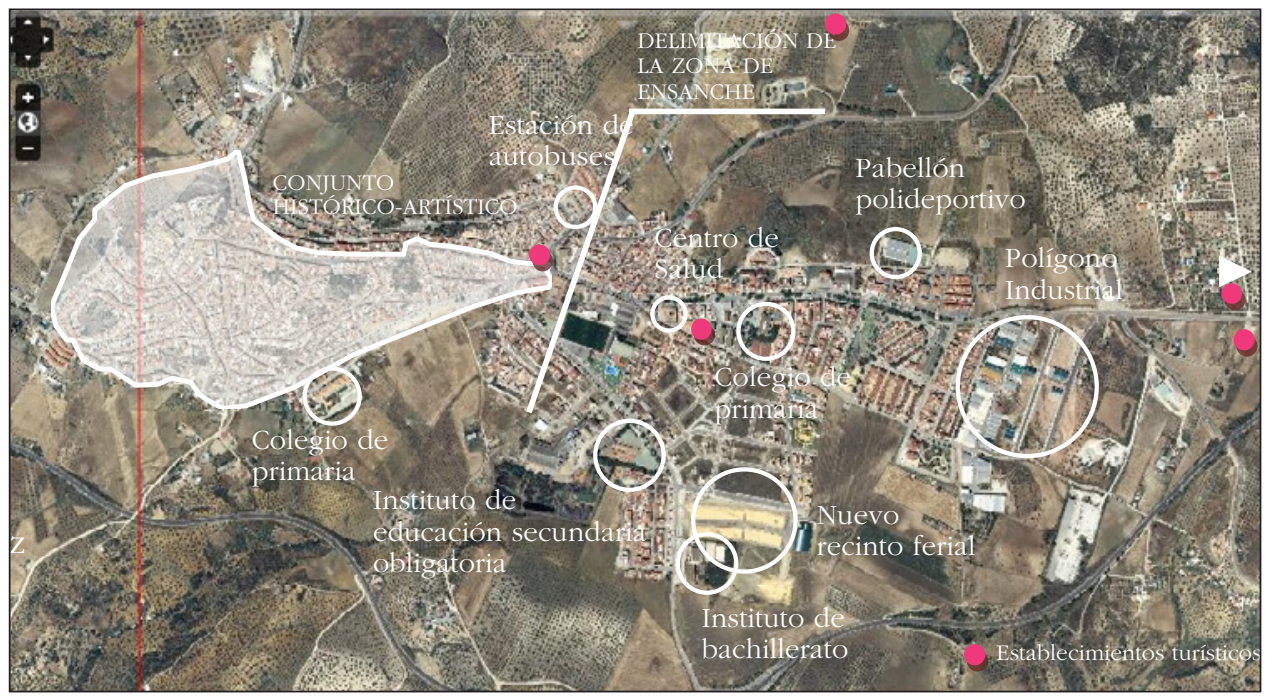

Fuente: Adaptación a partir del Comparador WMS Ortofotos, Canal Rediam, Consejería de Medio Ambiente y Ordenación del Territorio de la Junta de Andalucía. 
En definitiva, en las últimas décadas se verifica un crecimiento del parque de viviendas y edificios ${ }^{16}$, un desplazamiento de la ciudad hacia el Este y un arrinconamiento del casco histórico. Esta expansión espacial no se corresponde con un paralelo crecimiento demográfico. Todo ello ha tenido amplias repercusiones sobre la vida social y cultural de Olvera, de las que destacamos dos principales relacionadas con nuestra investigación:

1. La relocalización de las instituciones y servicios.

2. La marginación de los bienes patrimoniales más emblemáticos en una zona crecientemente despojada a efectos socioculturales, especializada en el turismo.

\section{Gráfico 1 \\ EVOLUCIÓN DEMOGRÁFICA DE OLVERA \\ (1950-2014)}

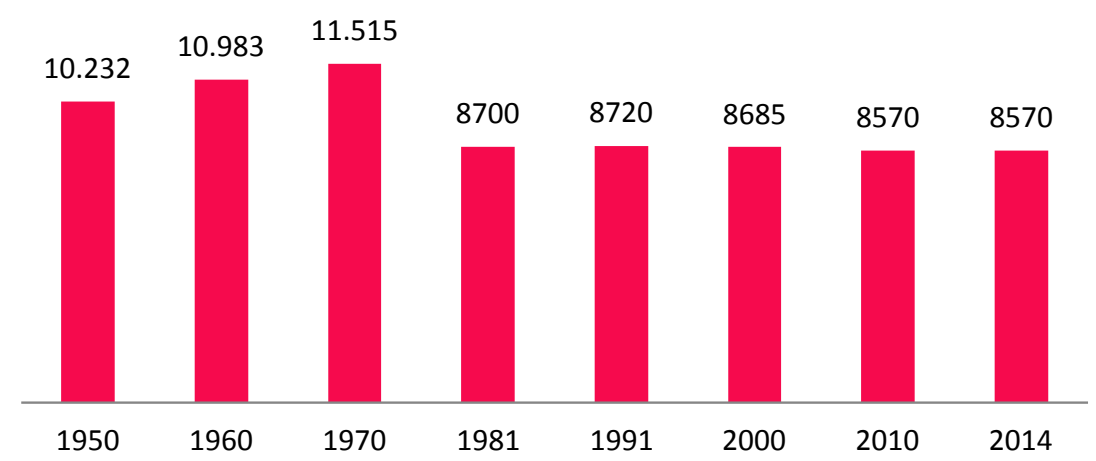

Fuente: elaboración propia a partir de datos del Instituto Nacional de Estadística.

\subsubsection{Zahara de la Sierra}

El caso de Zahara dista del anterior en cuanto al crecimiento del núcleo urbano, mucho menos significativo en los últimos cincuenta años. Su orografía presenta bastantes similitudes con la de la localidad olvereña, emplazándose en una elevación rocosa que culmina en un Castillo medieval a partir del cual se distribuyen las calles, adaptándose la trama urbana a la pendiente del terreno. Hasta el siglo XVIII la población se asentaba en una zona contigua al Castillo, antes de trasladarse a un área más confortable, por lo que las edificaciones de la actual Zahara no presentan restos constructivos anteriores a esa fecha.

Entre las décadas de 1970 y 1980 comenzaron a construirse numerosos inmuebles en la zona perimetral del núcleo urbano así como en las parcelas sin edificar que quedaban entre las casas, terrenos de propiedad municipal que eran vendidos a vecinos para la ampliación de casas contiguas. El Conjunto Histórico-Artístico fue declarado en $1983^{17}$ y, dos años más tarde, en 1985, se procedió a la inclusión del término municipal en el Parque Natural

16 Llegando a ocupar el suelo construido en la localidad alrededor de 115 hectáreas en el año 2015.

17 Inscrito en el Catálogo General del Patrimonio Histórico de Andalucía. 
Sierra de Grazalema ${ }^{18}$ a la vez que era declarado Bien de Interés Cultural el Castillo de Zahara por la Junta de Andalucía ${ }^{19}$. Otro bien de relevancia histórica, el Puente Romano, fue desmontado pieza a pieza ese mismo año ante el inminente comienzo de las obras de la presa de Zahara. Nunca más volvería a ser reconstruido y sus piezas se han perdido con el tiempo a pesar de las continuas propuestas de recuperación. También el puente de principios del siglo XX que daba acceso a la localidad a través de la carretera de Algodonales fue demolido en 1985.

\section{Figura 5 \\ ZAHARA: ORTOFOTO 1956-57}

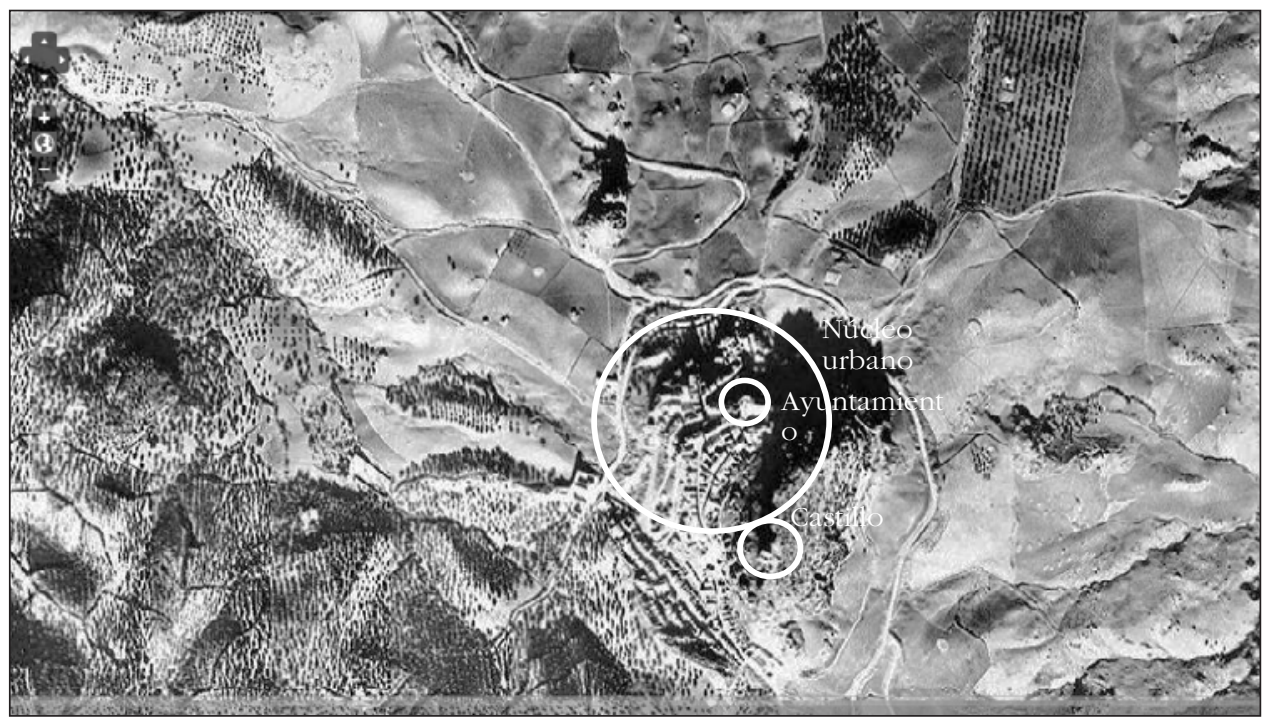

Fuente: Adaptación a partir del Comparador WMS Ortofotos, Canal Rediam, Consejería de Medio Ambiente y Ordenación del Territorio de la Junta de Andalucía.

El poco desarrollo industrial que ha tenido la localidad y su aislamiento relativo ha posibilitado el mantenimiento de una organización urbana más tradicional, influida por el reducido número de habitantes zahareños. La singularidad urbanística y el mantenimiento de una estética tradicional le valieron a Zahara, en los setenta, reconocimientos y premios tanto a nivel nacional como regional y provincial ${ }^{20}$. Las nuevas infraestructuras y servicios que comenzó a promover el consistorio durante las décadas de 1980 y 1990 se instalaron en la parte Norte del núcleo urbano, un área de expansión urbanística en la

18 Declarado el 13 de febrero de 1985 por la Consejería de Medio Ambiente de la Junta de Andalucía.

19 Inscrito en el Catálogo General del Patrimonio Histórico de Andalucía.

20 La Diputación de Cádiz concedió en 1966 a Zahara de la Sierra el Premio Anual de Embellecimiento y Mejora de los Pueblos Gaditanos. En el año 1971 recibe el Premio Nacional de Embellecimiento y Mejora de los Pueblos Españoles, por el Ministerio de Información y Turismo. Y cuatro años más tarde es galardonado con el Primer Premio de Embellecimiento de los Pueblos de la Provincia. 
Figura 6

LOS DOS PUENTES SOBRE EL GUADALETE EN 1970

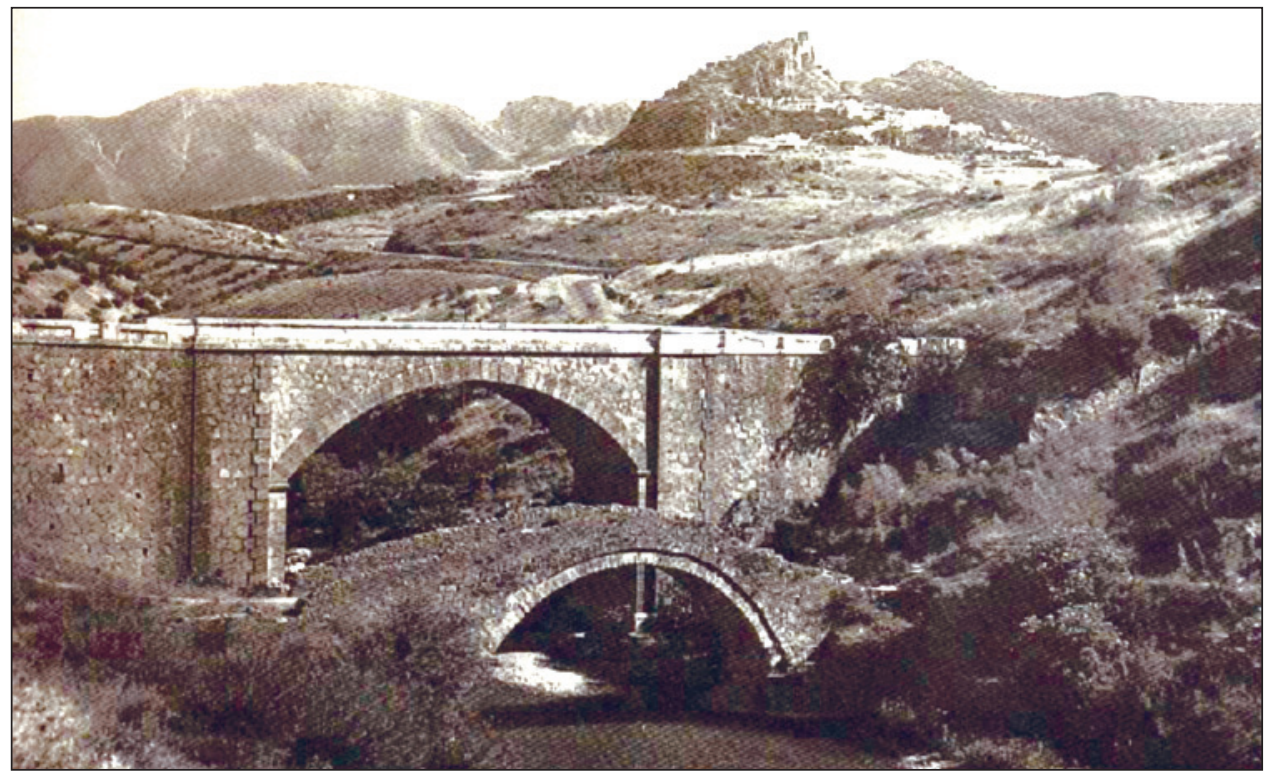

Fuente: José Santiago Horrillo.

Figura 7

ZAHARA: ORTOFO 2010-11

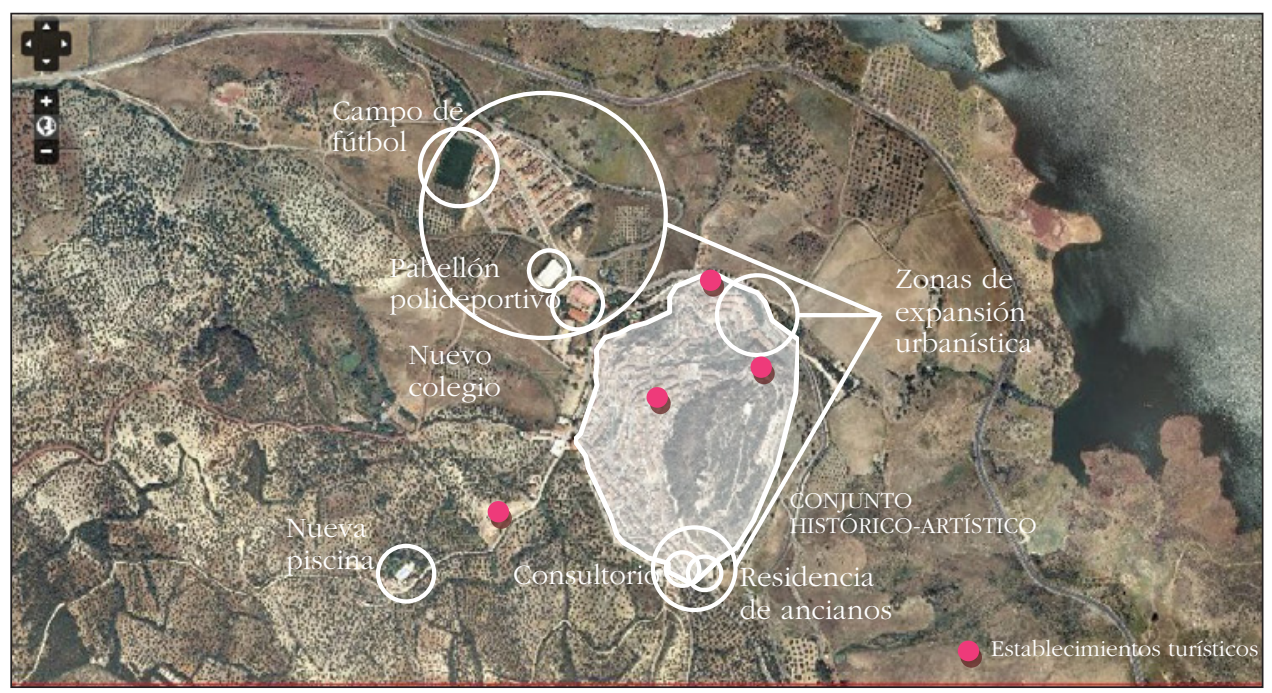

Fuente: Adaptación a partir del Comparador WMS Ortofotos, Canal Rediam, Consejería de Medio Ambiente y Ordenación del Territorio de la Junta de Andalucía. 
que fueron edificados colegios, zonas deportivas, de ocio y residenciales bajo la tendencia a una expansión regulada, con planes parciales o la aprobación definitiva de las Normas Subsidiarias en 199921. Esto ha conllevado la delimitación de los tres barrios que actualmente conforman la trama urbana zahareña, con un desplazamiento de los servicios hacia las zonas más nuevas.

La importancia que tiene la imagen de Zahara en el desarrollo turístico que ha sufrido la localidad en la última década se evidencia en el significativo papel que ha tomado esta actividad en la economía municipal. Y aunque tardó veinte años en abrirse el segundo establecimiento hotelero en la ciudad, en 1998, el interés por el sector es también palpable en la especialización hostelera de los negocios ubicados en la calle comercial que discurre entre los principales bienes monumentales.

Como en el caso de Olvera, aquí las épocas de mayor crecimiento urbano no se corresponden con años de aumento poblacional. La expansión constructiva busca nuevas comodidades venidas por una orografía más llana, como ocurriese desde la edad moderna, y un alejamiento de los corsés impuestos por las declaraciones legales de bienes de conjunto. El desplazamiento de los servicios hacia nuevas áreas con edificaciones más eficientes, en calles donde el estacionamiento de vehículos resulte más cómodo, conlleva a la población local a replantear la mejor ubicación de su residencia, y al hacerlo, esto incide nuevamente en la recolocación de los servicios, en una búsqueda constante por estar más cerca de los habitantes.

\section{Gráfico 2 \\ EVOLUCIÓN DEMOGRÁFICA DE ZAHARA DE LA SIERRA (1950-2014)}

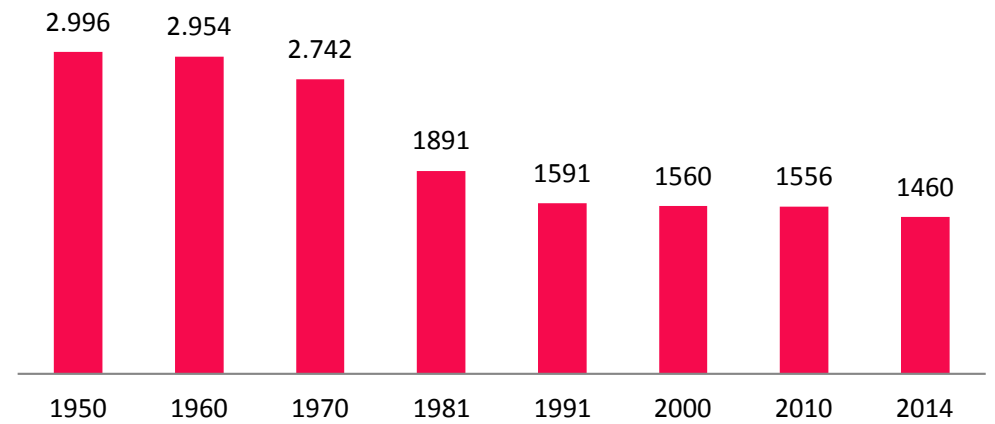

Fuente: elaboración propia a partir de datos del Instituto Nacional de Estadística.

Las repercusiones más importantes que estos fenómenos han tenido en Zahara de la Sierra son, pues, las siguientes:

La fragmentación espacial de la sociedad que no se traslada a otros barrios para realizar sus quehaceres diarios y que cada vez más apuesta por las zonas de expansión para establecer su residencia, promoviendo una cada vez mayor diferenciación en tres del área urbana.

21 En 1988 se redactan las normas subsidiarias de planeamiento municipal de Zahara, aprobadas inicialmente en 1993. Igualmente se redactan planes parciales como el de la zona del Peñón de la Horca, nueva ramificación urbanística al Norte de la localidad. 
La relegación de los bienes patrimoniales principales, en el casco antiguo, que quedan confinados a la mera contemplación.

\subsection{Principales actores participantes en el conflicto, relaciones y discursos}

Se consideran agentes implicados aquellos considerados por la colectividad hacedores de acciones que afectan al patrimonio local y su interés turístico. En la Sierra de Cádiz fueron entrevistados un total de 26 agentes de los dos municipios analizados, que son encuadrados en tres categorías diferentes:

a. Políticos gobernantes: aquellas personas que poseían o habían ejercido algún cargo político en los gobiernos locales durante la época democrática.

b. Políticos opositores: aquellos cuyo cargo político siempre había estado ligado a la oposición, no habiendo llegado a ejercer tareas de gobierno.

c. Agentes no políticos: párrocos, cronistas oficiales, antropólogos locales, empresarios, presidentes de asociaciones y delegados de hoteles. Éstos son actores que tienen una relación directa con el patrimonio y el turismo de forma laboral o institucional, y por consiguiente han desarrollado acciones que han afectado a los mismos en el periodo temporal estudiado.

Es preciso señalar que algunos de estos agentes responden a más de un perfil. La relación entre el patrimonio y la gestión política adquiere una relevancia notable, pues son en última instancia los órganos de gobierno los que clasifican los elementos considerados patrimoniales por parte de la ciudadanía. Así, es la política la que define el patrimonio y contribuye a la construcción de la identidad social de un pueblo (Zamora, 2011). La línea que aquí se defiende incide en la importancia del consenso objetivo acerca de lo que la propia sociedad considera patrimonio a través de todos los grupos sociales.

\subsubsection{Olvera}

En Olvera, la hegemonía en el gobierno local del PSOE se extiende casi desde 1979 hasta 2007, así, las medidas tomadas desde la administración pública municipal responden mayoritariamente al discurso de un único partido.

Los primeros años de democracia en Olvera, como en muchos municipios españoles, se caracterizan por un intento de desarrollo económico de mano de la industria, con políticas que tienen como fin último el de mantener el proyecto democrático que comienza. Juan García, concejal de la oposición del PCE entre 1979 y 1983 defiende: "Cuando yo estaba en el Ayuntamiento nos preocupábamos de que el chozajo no se nos viniera abajo, es decir, empezábamos un cambio democrático de una dictadura, y nuestro interés era que no se nos fundiera ese proyecto; ese era nuestro mayor valor".

Es a partir de 1983, con la catalogación del Conjunto Histórico-Artístico, y inclusión en las Normas Subsidiarias municipales de una zona de especial protección para el mismo, cuando aumenta la sensibilidad entre los responsables políticos y la sociedad en general por el patrimonio y los beneficios que éste puede reportar a nivel económico. 
No obstante, esto no es valorado por los agentes implicados de igual forma. Los que gobiernan tras la aprobación de las Normas Subsidiarias entonan un mea culpa general al reconocer no haberlas gestionado de la mejor forma, y es que desde el ámbito político se subraya el coste electoral que esto puede tener. Unos pocos, como Remedios Palma, concejal del PSOE y responsable de varios proyectos urbanísticos en el casco antiguo $^{22}$, recalcan las diferencias que existen entre Olvera y otros municipios cercanos como Zahara o Grazalema donde, apenas sin normas urbanísticas, la gestión de la gobernanza local en materia patrimonial fue más eficiente y el resultado posterior es el de una ciudadanía "consciente de la riqueza que aporta el vivir en un lugar estéticamente armonioso con el entorno". Otros sectores tanto políticos como patrimonialistas critican la supeditación de las Normas Subsidiarias al equipo de gobierno y su aplicación desigual según el criterio de los gobernantes en cada momento. Defienden la existencia de un crecimiento urbano local en el que han priorizado los intereses personales, la especulación urbanística, ocasionando con el paso del tiempo un modelo inestable que ha dado pie a un abandono poblacional del casco antiguo y el inicio de un proceso e museificación del mismo.

En las entrevistas realizadas a los agentes implicados en la gestión turística del patrimonio, éstos ponen el acento en los bienes monumentales de la localidad, privilegiándolos en detrimento de la arquitectura vernácula con valor etnológico. Sin embargo los agentes independientes a las instituciones reprochan a los gobernantes locales la pérdida durante años de gran parte del patrimonio cultural, en muchas ocasiones por dejadez de los mismos y por obviar su valía, permitiendo que gran parte de la riqueza arquitectónica del casco histórico se pierda con la demolición de casas antiguas y edificios de gran valor patrimonial. Y es que se identifica un deseo en la clase política olvereña de crear un núcleo urbano con características más propias de ciudades grandes y medias que de pueblos, lo que ha conllevado en gran medida a la degradación social del patrimonio etnológico y tradicional doméstico y la consecuente pérdida material del mismo. El antropólogo y secretario general de la Asociación Pablo de Olavide para la defensa del Patrimonio Cultural Andaluz, Alberto Moreno, denuncia esta visión monumentalista del patrimonio que apenas tiene presente la vertiente etnológica del mismo, ante cuya pérdida se queda impasible, una visión generalizada venida desde los sectores culturales e intelectuales.

Aunque todos coinciden en la recuperación de la Vía Verde de la Sierra ${ }^{23}$ y la Casa de la Cilla ${ }^{24}$ como los hitos más importantes en la puesta en valor del patrimonio local, a su

22 Proyectos de mejora y embellecimiento de la subida al barrio de La Villa y puesta en valor de este mismo barrio en 2003; obras de restauración del Castillo; proyecto de Puesta en Valor del Patrimonio Rural de la Sierra de Cádiz con el adecentamiento del Peñón del Cerretillo; nuevo Plan de Tráfico con objetivo de descongestión de tráfico rodado en el Conjunto Histórico-Artístico; reordenación urbanística del mismo paralela a las I Jornadas de Urbanismo en 2005.

23 Proyecto ecológico turístico de la Vía Verde del Ferrocarril de la Sierra, con la recuperación del trazado a través de la restauración del camino y la rehabilitación de antiguas estaciones como centros de acogida, que comienza en 1994 y para la gestión de la cual se crea en el año 2000 una fundación.

24 Antiguo granero propiedad de los Duques de Osuna en la Plaza de la Iglesia, adquirido en 1987 durante la época de Francisco Menacho como alcalde y transformado en centro cultural, oficina de turismo y museo etnográfico, siendo inaugurado en 1999 tras varias intervenciones a través de escuelas taller y concesiones. 
vez denuncian que éste siempre ha sido un sector infravalorado en la economía municipal. En general, sus perspectivas del sentido de puesta en valor varían de la siguiente forma:

a. Desde los grupos políticos se defiende unánimemente la idea de que esto es sinónimo de promoción, así el concepto de explotación turística está intrínsecamente unido.

b. Desde las clases empresariales esa puesta en valor debe poseer un sentido más comercial, pues no tendría sentido por tanto para estos agentes la inversión en patrimonio sin esperar recibir recompensa en sentido mercantil.

c. Las personalidades más involucradas en la recuperación de bienes materiales e intangibles olvereños, por su parte, defienden que la recuperación y la difusión entre la ciudadanía es un deber que no debe obviarse, y ahí radica la puesta en valor del patrimonio.

Todos valoran igualmente como uno de los temas que mayor repercusión tiene en la gestión del patrimonio cultural la poca participación ciudadana en su mantenimiento. Algunos lo atribuyen a una mala gestión política durante los años en que comenzó la expansión urbanística olvereña, y todos ven en este fenómeno un hecho negativo para la sociedad, que ha visto cómo su localidad quedaba dividida en dos. En varias ocasiones se han previsto medidas para paliar este fenómeno, con programas de rehabilitación urbanística, sin embargo desde el sector político se lamentan de no haber puesto en marcha políticas más efectivas para frenarlo. También es algo común en todos los grupos entrevistados la preocupación por la necesidad inmediata de un proyecto de regeneración urbana en el Conjunto Histórico-Artístico.

Afirman desde la política que el turismo comenzó a ser una preferencia en la gestión local a partir de finales de la década de 1990, y defienden la iniciativa de la actividad privada, que debe ser, dicen, la que lleve las riendas del desarrollo turístico del municipio. Muchos agentes ven en la Sierra de Cádiz un territorio abandonado por las autoridades, otros, la mayoría, ve una relación de conflictos entre las distintas instituciones territoriales, y casi ninguno conoce la existencia de la Iniciativa de Turismo Sostenible que se desarrollara entre 2007 y 2010 en la comarca, muy polémica por la falta de adecuación entre lo propuesto y lo ejecutado ${ }^{25}$, y con diversas actuaciones en la localidad.

Cuidar y tratar el rico patrimonio olvereño es un requerimiento esencial y primordial para la mayoría de los agentes implicados en este estudio, que ven en él el futuro de la economía local, palabras de las que se deduce que no supone para muchos de estos actores una actividad protagonista en el presente de Olvera.

25 Iniciativa coordinada por la Consejería de Turismo, Comercio y Deporte de la Junta de Andalucía y la Mancomunidad de Municipios de la Sierra de Cádiz de la que participaban los diecinueve municipios que componen la comarca, con un presupuesto total de 8.459.864,12 euros. No se llevaron a cabo muchas de las iniciativas propuestas, a la vez que se intervino en actuaciones que no estaban recogidas en la presentación del plan y que fueron compiladas en anexos posteriores como: el Centro de Interpretación Ciudad de Arcos, en Arcos de la Frontera; Puesta en valor del Paseo de la Glorieta, en Villaluenga del Rosario; Reparaciones en la Iglesia Ntra. Sra. de la Encarnación, Olvera; Centro de Interpretación Turística Flora y Fauna Sierra de Grazalema, en Grazalema; y así hasta catorce actuaciones no planteadas inicialmente y muy vinculadas a la generación de nuevas infraestructuras. Fuente: Mancomunidad de Municipios de la Sierra de Cádiz (2007): Programa de Turismo Sostenible Sierra de Cádiz. 


\subsubsection{Zahara de la Sierra}

De las nueve legislaturas políticas que se han desarrollado en Zahara desde 1979, el PSOE ha gobernado en seis de ellas. Tan solo en las iniciadas en 1979, 1987 y 2003 ha gobernado un partido político diferente. Y al igual que ocurriera en el municipio de Olvera, los discursos establecidos por los actores políticos de las primeras etapas enfatizan en las necesidades sociales en una época en la que en la actividad turística aún no contemplaba los segmentos rural y natural, pilar fundamental en el desarrollo económico zahareño en la actualidad.

Las entrevistas revelan que la preocupación por mantener el patrimonio material e inmaterial del que la sociedad es depositaria es común en todos los agentes involucrados durante los treinta y seis años de democracia en Zahara, al menos en su discurso actual, coincidiendo mayoritariamente en destacar los principales inmuebles civiles y religiosos como los más importantes emblemas del mismo. En 1983 es nombrado alcalde Juan Ortega, al que su discurso en favor del respeto de la estética común por medio de sanciones económicas le hace abandonar la política activa al finalizar esa legislatura por disputas con algunos sectores de la ciudadanía. Así, este discurso en torno al patrimonio va evolucionando desde la concepción general más restrictiva en cuanto a un patrimonio centrado en los bienes inmuebles más representativos, a un discurso más holístico que interpreta el patrimonio como un conjunto inseparable que integra bienes históricos, artísticos y etnológicos, aunque existen matices, ya que en todos los grupos implicados, tanto a nivel político como social y empresarial, la mayoría de las voces siguen poniendo el énfasis patrimonial en dichos monumentos.

La identidad colectiva de la población zahareña se ha caracterizado desde hace décadas por su movilización en favor de su patrimonio cultural, posibilitando, por ejemplo, la declaración de Fiesta de Interés Turístico Nacional del Corpus Christi ${ }^{26}$. Tras una época de tensión política, en 2014 el patrimonio volvió a tener un rol protagonista en la celebración de una recreación histórica, actividad que ha sido valorada muy positivamente desde todos los sectores como impulsora de la cohesión social en torno al patrimonio local.

El modelo turístico que despegará en la localidad se percibe en el discurso de sus gobernantes de principios de los noventa, que defienden que la sociedad local comienza a valorar la necesidad de conservar la esencia urbanística y monumental teniendo como ejemplo municipios vecinos que se valen de ello para atraer visitantes, mientras que en otras localidades se ha articulado un sistema económico industrial que ha propiciado la pérdida de gran parte de su patrimonio arquitectónico doméstico. Así, los agentes valoran la continua presencia de proyectos arqueológicos en Zahara durante las décadas de 1990 y $2000^{27}$

26 Declarada Fiesta de Interés Turístico Nacional el 24 de abril de 1980 por el Ministerio de Comercio y Turismo.

27 En 1993 se inician por primera vez unas excavaciones arqueológicas en el interior de la fortificación musulmana zahareña, dentro del proyecto general de Intervenciones en Áreas de Interés Turístico-cultural de la Sierra de Cádiz. En 1996 se lleva a cabo la primera fase de un proyecto para la limpieza de los restos arquitectónicos y su documentación, consolidación de las estructuras, y la creación de la infraestructura necesaria para la puesta en funcionamiento de visitas. En 1997 se reinician las intervenciones incluidas en el proyecto denominado Recuperación y Puesta en valor de yacimientos arqueológicos de la Sierra de Cádiz, tomando la denominación de Ruta Arqueológica de los Pueblos Blancos; se pone en marcha la Escuela Taller Foro Arqueológico para la 
como elemento esencial para la concienciación social con la puesta en valor del patrimonio municipal y su importancia como fuente de riqueza directa a través de la actividad turística.

Los discursos en torno a las declaraciones de protección son variables. Desde el punto de vista de muchos de los agentes políticos, empresarios y ciudadanos, la declaración de Parque Natural, de Conjunto Histórico-Artístico así como las restricciones impuestas por la Confederación Hidrográfica del Guadalquivir con motivo de la construcción de la presa suponen un lastre para el desarrollo de Zahara, un corsé que dificulta una gestión propicia para el beneficio de los ciudadanos. Algunos como Josefa Calle, alcaldesa del PSOE durante la legislatura que comienza 2007 o María José Pico, concejal del PP, exponen como ejemplo las dificultades para construir un polígono industrial que potencie el desarrollo fabril o una gasolinera, sin embargo también creen casi consensualmente en las ventajas y reconocimientos que estas catalogaciones conllevan para el municipio.

La aprobación de las Normas Subsidiarias en 1999, once años después de su redacción, también es motivo de conflicto, pues desde todos los partidos políticos se critica que éstas constituyen un texto no conformado de forma participativa, sino de espaldas a políticos y vecinos, y cuestionan por tanto su efectividad, ya que fueron articuladas de manera externa, por profesionales de instituciones comarcales con un menor conocimiento directo de la realidad local de Zahara. También, desde los partidos relegados históricamente a la oposición y desde algunos sectores socialistas se ha criticado de forma continuada la consecución de proyectos que han buscado garantizar puestos de trabajo temporales en la localidad, lo que ha conllevado a una falta de proyección futura de la mayoría de planes.

El razonamiento que se hace del sector turístico desde el ámbito empresarial y desde los tres partidos con presencia institucional en las últimas legislaturas es de falta de infraestructura, por ejemplo de estacionamientos, así como de escasa cooperación entre agentes. Se aprecia una polarización entre el sector empresarial y administrativo: desde la administración se critica a los empresarios por no contribuir a crear un destino de calidad al ponerse de acuerdo para cerrar los negocios el mismo día de la semana; mientras que, por su parte, los empresarios critican la presencia de establecimientos de gestión pública, con una oferta de precios desleal. Así pues, se identifican dos vías de gestión turística paralela, pública y privada, que se percibe también en las críticas mutuas sobre el estado de las infraestructuras municipales.

consolidación de la Ruta Arqueológica como atrayente turístico, promotora de empleo y salvaguarda del patrimonio con excavaciones en Puerta de La Villa e intervención en la muralla, y se lleva a cabo la rehabilitación de la Antigua Iglesia de Zahara para Centro de Recepción e Interpretación del Yacimiento Arqueológico de Villa Medieval. En el año 2000 nace el taller de empleo Arte Antiguo para reparación, conservación y reproducción en cerámica y forja de piezas de arte antiguas y prehistóricas y la construcción, restauración y rehabilitación de edificios y construcciones en Olvera, Zahara de la Sierra, Benaocaz y Arcos de la Frontera. En 2005 el Taller de Empleo Nazarí comienza los trabajos de consolidación de la Puerta de La Villa y de los lienzos occidentales de la cerca externa de la muralla y dos años más tarde, en 2007 el Taller de Empleo Sajrat' Abbad pone en valor de los Tramos C y D de la cerca externa oriental, y lleva a cabo intervenciones menores en el atrio de la antigua iglesia y excavación de la Casa de Fuentes (Cisterna romana). En 2008 se proyecta otra obra de intervención arquitectónica en la muralla islámica y en 2010 el Ayuntamiento y la Universidad de Cádiz llevan a cabo un programa de prácticas sobre arqueología medieval con alumnos de la institución académica; ese mismo año los Talleres de Empleo Arte Antiqua y Nazarí se encargan de la limpieza de la vegetación existente en la muralla. 


\subsection{Actuaciones turísticas y urbanísticas en torno al patrimonio}

Es preciso ahora analizar las principales acciones fomentadas por los agentes implicados tras conocer sus discursos en torno a la gestión del patrimonio cultural y a la importancia del turismo en la regeneración urbana y la actividad social de los municipios, valorando la correspondencia de los discursos con la realidad de los casos de estudio.

\subsubsection{Olvera}

Durante la primera legislatura democrática las principales medidas en torno al patrimonio tienen lugar en el casco histórico, con la consolidación de la peña del Castillo, en una época en la que las preocupaciones políticas y sociales discurren por otros derroteros. A la vez que es declarado el Conjunto Histórico-Artístico de Olvera y se organiza el Premio Juan Colunga de investigación en historia local, se pone en marcha la urbanización de un polígono industrial debido al objetivo industrializador imperante. Nacen entonces las Normas Subsidiarias de planeamiento con propuestas de rehabilitación del patrimonio residencial y urbano, aunque paradójicamente las intervenciones se restringen a los bienes monumentales, quedando abandonado gran parte del parque de viviendas tradicionales. El Ayuntamiento se incorpora entonces al Patronato Provincial de Turismo, y destina un nuevo edificio en el ensanche a hotel de gestión pública a la vez que se construye otro establecimiento de carácter privado a las afueras.

Las legislatura políticas de la década de 1990 comienzan con la compra de una serie de edificios que incrementan el patrimonio municipal entre los que destaca La Cilla, de gran valor histórico, donde se llevan a cabo obras de rehabilitación transformando una de sus alas en museo etnográfico. Más tarde se inicia el proyecto ecológico-turístico de la Vía Verde del Ferrocarril de la Sierra, muy relevante en el plano patrimonial y turístico, recuperándose parte del trazado de la antigua vía ferroviaria con la restauración del camino para caminantes y ciclistas, y la rehabilitación de las estaciones. Se inician obras para la puesta en valor del viario histórico local que se extienden varios años, y que inciden en el embellecimiento del casco histórico por medio de escuelas taller. Igualmente se inauguran una nueva entrada al Castillo, la Iglesia Parroquial tras unas obras de restauración y la nueva Plaza de la Iglesia, muy criticada por su línea arquitectónica contemporánea.

En 1999 el Castillo de Olvera se integra en la Ruta Arqueológica de los Pueblos Blancos, llevándose a cabo labores de consolidación y puesta en valor, y un año más tarde tienen lugar por primera vez las Jornadas de Historia Local. Posteriormente se llevan a cabo obras de restauración en las murallas y el Castillo, inauguradas en 2005, y se desarrolla un proyecto de reordenación urbanística del Conjunto Histórico-Artístico a la vez que se redacta un nuevo plan de tráfico para éste con objeto de ser descongestionado. Varias jornadas en los años siguientes persiguen acercar el patrimonio a la ciudadanía, así como su difusión y musealización. Con nuevos planes parciales de urbanización y el desplazamiento de más servicios continúa la tendencia de consolidación del ensanche en la década de los noventa. 
En el ámbito turístico, se constituye una Mesa de Turismo ${ }^{28}$, se dota de iluminación al Peñón del Sagrado Corazón y se mejora el acceso a la estación de la Vía Verde, convertida en hostal. Y poco después se pone en marcha un plan turístico para la Vía Verde ${ }^{29}$ y se incluye a Olvera en la Ruta de los Almorávides del Legado Andalusí en 2003.

Después de una hegemonía clara del PSOE en el gobierno local, las elecciones de 2007 permiten al grupo municipal de IU gobernar con el apoyo del PP. En estos años un taller de empleo acondiciona edificios públicos en el Conjunto Histórico-Artístico, donde además se acondiciona una nueva zona verde aprovechando el patrimonio natural del mismo, y se ponen en marcha nuevamente obras de reparación de la Iglesia Parroquial tras un incendio. En 2011, bajo iniciativa privada de la familia Álvarez Colunga, se abre un camping en el término municipal, un recurso turístico nuevo que amplía la oferta alojativa de la localidad, y tres años más tarde se crea la Asociación Olvera Temática para la promoción turística local por parte de los empresarios locales.

\subsubsection{Zahara de la Sierra}

En Zahara, la principal preocupación durante la primera legislatura democrática es la de configurar un mayor bienestar social. Caso etnológico llamativo es la festividad del Corpus Christi, para la que se solicita la declaración de Fiesta de Interés Turístico Nacional ya en 1979 bajo iniciativa popular.

En 1981 se redacta un proyecto decisivo en el devenir zahareño: la construcción de la presa. Esto hace que se apruebe el desmontaje de uno de los iconos patrimoniales más representativos de Zahara, el Puente Romano, materializándose así el discurso coetáneo que relega el patrimonio a un puesto secundario en las preocupaciones políticas, sin embargo, el hecho de que se proyecte su reconstrucción apunta a una ligera inquietud por el patrimonio de carácter monumental. Se declara paralelamente, en 1983, el Conjunto Histórico-Artístico de Zahara, uno de los primeros de la comarca, y, de forma paulatina, se comienza a vincular el desarrollo de la localidad con la puesta en valor de su patrimonio. Se llevan a cabo obras de consolidación del Castillo, justificando oficialmente la seguridad para la ciudadanía por el desprendimiento de rocas, sin alegar causa alguna relacionada con su puesta en valor, sin embargo son varias las actuaciones que comienzan a desarrollarse para el embellecimiento y disfrute monumental durante la década de 1980. Época en la que también se erigen algunas construcciones disonantes con la estética global del pueblo, siendo el Ayuntamiento quien financia la mayor parte de las intervenciones de reposición de estos inmuebles, asumiendo la responsabilidad del problema.

Coincidiendo con la tercera legislatura, la primera de un partido político independiente en Zahara (Unión Independiente de Zahara, UNIZA), se enfatiza el discurso turístico con la participación en el Patronato Provincial de Turismo o el adecentamiento urbano general, y se promueven valores locales a través de cursos de artesanía y el realce del Corpus. La finalización del embalse fomenta la creación de varias escuelas taller relacionadas con

28 De la que no existen referencias documentales sobre su composición ni proyectos llevados a cabo.

29 La Consejería de Turismo y Deporte, la Fundación Vía Verde y Consorcio Vía Verde pusieron en marcha de un plan turístico para esta vía en 2003 que atendía al estudio y diseño de políticas de promoción, la puesta en valor y el uso de recursos turísticos, el desarrollo de una oferta turística y la creación de nuevos productos. 
las disciplinas patrimonial y turística y se inician unas excavaciones arqueológicas en el Castillo que suponen uno de los primeros intentos de recuperación patrimonial de la Sierra de Cádiz, convirtiéndose así el municipio en ejemplo de la experiencia de los programas europeos en la diversificación económica rural con LEADER y LEADER II. Se aumenta la oferta turística con un hostal de titularidad municipal y se instala por primera vez una señalización del patrimonio histórico.

Son años de vital importancia para comprender el desarrollo urbano sufrido en la localidad, pues son adquiridos unos terrenos por parte de la administración municipal con el fin de garantizar el crecimiento ordenado de Zahara y se pone en marcha una campaña de concienciación a vecinos y constructores sobre la necesidad de respetar la tipología tradicional de las edificaciones. Se denota la búsqueda de implicación popular en la consecución de objetivos patrimoniales a largo plazo para garantizar su buen desarrollo. Igualmente se lleva cabo la primera fase de un programa de recuperación arqueológica que pretende explotar turísticamente los restos zahareños, siendo uno de los proyectos más polémicos el de la construcción de un centro de recepción en la Antigua Iglesia de Zahara, denunciado por muchos como atentado contra la estética del lugar y que para otros supone una inversión inútil que ha quedado en desuso con el paso del tiempo ${ }^{30}$. Se inician proyectos arqueológicos en los que los ciudadanos participan activamente, generando la proliferación de vecinos formados en actividades relacionadas con los bienes patrimoniales y su puesta en valor y se expanden los negocios en la zona donde se ubican los principales recursos monumentales, lo que hace que el consistorio solicite la declaración de Zona de Gran Afluencia Turística, credencial que finalmente no le es concedida.

Durante un gobierno por coalición entre PA y PP, se editan varias publicaciones sobre el patrimonio cultural de Zahara a la vez que tienen lugar más trabajos de consolidación de la muralla. La política local se centra en el adecentamiento urbano, la eliminación del cableado y la iluminación ornamental de los monumentos. Y el regreso al gobierno municipal del PSOE continúa en esta línea con el trabajo de varios módulos de escuelas taller en la zona arqueológica de Zahara, la apertura de nuevos itinerarios de visitas y establecimiento de cartelería interpretativa. Las labores investigadoras ya no sólo se ciernen al patrimonio monumental, natural y arqueológico sino que también abarcan parte de los archivos documentales del municipio.

En el plano turístico es presentado un proyecto para la creación de un camping en el término municipal de iniciativa particular, finalmente denegado debido a las restricciones que presentan las catalogaciones a las que se acoge el término. El discurso en contra de las restricciones se basa en gran parte en hechos como éste.

En 2012 tiene lugar la I Jornada sobre Conservación del Patrimonio Natural y Cultural de la Reserva de la Biosfera y se pone en marcha la I Recreación Histórica Medieval de iniciativa ciudadana. En la última década el sector turístico se diversifica y ya no sólo se centra en el patrimonio, enfatizando en el segmento en alza del turismo deportivo y de aventura con la puesta en marcha de varias pruebas deportivas en el municipio y la creación de empresas de turismo activo.

30 Un proyecto de Julio Barreno Gutiérrez que es dotado de equipamiento en 2004 durante el gobierno del Partido Andalucista, a pesar de no creer en su funcionalidad ni estética. 


\section{CONCLUSIONES E IMPLICACIONES}

A partir de la década de 1980 surge una corriente que imprime un especial interés a las ciudades y pueblos históricos como destinos turísticos. Nacen nuevos planteamientos que buscan valorar el patrimonio cultural en su conjunto, para lo que comienzan a desarrollarse proyectos que velan por una conservación integral del mismo ligada al desarrollo de políticas urbanísticas y turísticas. Sin embargo, la búsqueda de una relación armónica entre patrimonio, urbanismo y turismo es una tarea compleja, ya que son disciplinas que responden a racionalidades distintas, enfrentan la rentabilidad económica con la defensa de los valores colectivos (Troitiño, 2015).

En la Sierra de Cádiz la década de 1990 y los primeros años del nuevo siglo se caracterizan por múltiples intervenciones arqueológicas promovidas por programas puestos en marcha desde las administraciones públicas supracomarcales, que buscan encontrar en su patrimonio un producto en torno al cual sostener el desarrollo turístico de la región en una época en la que el discurso social e institucional atiende especialmente al patrimonio de carácter monumental. Éste es un proceso llevado a cabo en todos los municipios de la comarca serrana así como en gran parte del territorio español, ejemplificado en este estudio por medio de los casos de Olvera y Zahara de la Sierra.

Estas prácticas, sin embargo, no han evitado el desplazamiento de la población hacia zonas geográficas con mayores comodidades, en gran parte de los casos alejadas de los centros históricos emplazados desde hace siglos en riscos y peñas de carácter defensivo o a los pies de un castillo medieval -Arcos de la Frontera, Benaocaz, Bornos, Espera, Grazalema, Olvera, Setenil de las Bodegas, Torre Alháquime, Ubrique, Villaluenga del Rosario y Zahara de la Sierra-. Así, los cascos históricos de la mayor parte de los pueblos de esta comarca -fundamentalmente aquellos de origen medieval, así como otros de carácter post-islámicos como El Bosque o Villamartín- han ido quedando en una situación periférica $^{31}$, debido al traslado de los servicios hacia las zonas de ensanche, y con ellos un mayor desplazamiento de la población. El urbanismo municipal ha incentivado este fenómeno y las políticas turísticas han jugado un papel fundamental con la puesta en valor del patrimonio monumental para ser consumido por actores foráneos y pocas veces dirigido a la ciudadanía local.

En los dos casos de estudio, Olvera y Zahara, se diagnostica un fenómeno de museificación en las zonas históricas, esto es una especialización turística de los servicios existentes en las mismas, que comienza a evidenciarse a mediados de los años noventa y que apunta a ser más acentuado en los próximos años si la gestión que se hace de las políticas patrimoniales, turísticas, comerciales y urbanísticas no torna en modelos más próximos a las necesidades de la sociedad que habita en los conjuntos históricos de ambos municipios. Se está produciendo por tanto, en las últimas décadas, una división espacial en estas localidades: por un lado está la zona denominada A, museificada, aunque sin vida social o muy poca, fundamentalmente correspondiente a los barrios más antiguos de las poblaciones y donde se concentra la mayor parte de los bienes patrimoniales; y la

31 Actualmente existen alrededor de trescientas viviendas vacías en el Conjunto Histórico-Artístico de la localidad de Olvera según se describe en un informe realizado por la Oficina Municipal de Urbanismo.

Cuadernos de Turismo, 40, (2017), 13-43 
zona $\mathrm{B}$, dinámica, hacia donde se ha desplazado la población. Paradójicamente la dinámica demográfica es regresiva en casi todos los municipios de la comarca -a excepción de Ubrique-.

El que la población comprenda el patrimonio como algo reemplazable puede ocasionar a largo plazo una falta de reconocimiento de la identidad propia que puede conllevar la desaparición de gran parte de dicho patrimonio. Este es el caso de las construcciones residenciales ejemplo de la arquitectura tradicional de la zona, que desde hace décadas están desapareciendo para dar lugar a inmuebles en total disonancia con las construcciones tradicionales de estos municipios. Se ha producido así un abandono progresivo de las edificaciones tradicionales, pues las políticas implantadas han premiado en la mayoría de los casos los nuevos proyectos de construcción por encima de la rehabilitación de vivienda antigua con la redacción de numerosos planes parciales de urbanización al margen de los centros históricos, así como la asociación de esta tipología arcaica de inmuebles a la explotación turística. Aunque numerosos, los programas autonómicos de rehabilitación, con la concesión de ayudas económicas anuales, no han frenado la expansión de las nuevas construcciones.

Para propiciar una protección integral del patrimonio cultural es preciso, ante todo, contar con la participación de la ciudadanía, así como la existencia de una correlación entre las políticas patrimoniales, turísticas y urbanísticas municipales. Las medidas de concienciación ciudadana que desde hace décadas se han venido dando en Zahara permiten que a día de hoy la población comprenda que sus valores patrimoniales garantizan la existencia de una actividad turística fuente de riqueza económica, social y cultural para el municipio. En Olvera, sin embargo, la conciencia política y empresarial ha estado más ligada al desarrollo industrial y urbanístico, así, durante décadas no se ha apostado por una preservación de los valores culturales endógenos, y esta realidad es la que presenta una mayor presencia entre los diecinueve municipios de la comarca de la Sierra de Cádiz.

La situación que vive en la actualidad esta comarca se repite en otros lugares donde la importancia que tiene el patrimonio para el sector turístico ha sido vagamente considerada por los distintos agentes implicados y la sociedad local, originando una despatrimonialización paulatina de muchos elementos claves de su pasado. Es por ello conveniente estudiar las causas que han propiciado esta situación, para poder extrapolar las conclusiones a otros casos y profundizar en el estudio de la misma.

\section{REFERENCIAS BIBLIOGRÁFICAS}

AGUILAR CRIADO, E., SACCO DOS ANJOS, F. \& VELLEDA CALDAS, N. (2011): «Productos locales, calidad y diversificación: nuevas estrategias de desarrollo en el mundo rural de España y Brasil», Estudios Sociológicos, vol. 29, nº 85, pp. 189-214.

BALLART HERNÁNDEZ, J. \& JUAN I TRESSERRAS, J. (2008): Gestión del patrimonio cultural. Barcelona, Ariel.

BANDARIN, F. (2014): El paisaje urbano histórico: la gestión del patrimonio en un siglo urbano (José Miguel Gómez Acosta trad.). Madrid, Abada.

BECK, S. (2010): «Morals, Metaphysics and The Method of Cases», South African Journal of Philosophy, vol. 29, n 4, pp. 331-342. 
CASTELlANO LÓPEZ, A. M. (2012): La pérdida de identidad de los pueblos blancos de la Vía Verde de la sierra de Sevilla y Cádiz: trabajo fin de máster (María Rosario González Rodríguez y Cristina de la Orden Reyes, tutoras.). Sevilla, Universidad de Sevilla.

COBOS RODRÍGUEZ, L.M. (2003): Zahara. Memoria recuperada del patrimonio arqueológico. Zahara de la Sierra, Ayuntamiento de Zahara de la Sierra.

CONSEJERÍA DE CULTURA (2012): III Plan General de Bienes Culturales, documento para el debate. Junta de Andalucía. Disponible en http:/www.juntadeandalucia.es/ organismos/cultura/consejeria/sobre-consejeria/planes/detalle/36930.html

CONSEJERÍA DE EDUCACIÓN, CULTURA Y DEPORTE: Catálogo General del Patrimonio Histórico Andaluz. Junta de Andalucía. Disponible en http://www.juntadeandalucia.es/cultura/web/areas/bbcc/catalogo

CONSEJERÍA DE OBRAS PÚBLICAS Y TRANSPORTES (2006): Decreto 206/2006, de 28 de noviembre de 2006, Plan de Ordenación del Territorio de Andalucía. Junta de Andalucía. Disponible en http://noticias.juridicas.com/base_datos/CCAA/an-d2062006.html

CONSEJERÍA DE TURISMO Y DEPORTE: Plan General del Turismo Sostenible de la Junta de Andalucía. Junta de Andalucía. Disponible en http://www.juntadeandalucia. es/export/drupaljda/PGTSAH\%202020\%20Volumen\%20II\%20Consejo\%20Gobierno. pdf

CONSEJO NACIONAL DE LA CULTURA Y LAS ARTES (2012): Estudio diagnóstico del desarrollo cultural del pueblo RAPANUI. Disponible en http://www.cultura. gob.cl/wp-content/uploads/2013/01/INFORME-FINAL-ESTUDIO-DIAGNOSTICOPUEBLO-RAPANUI.pdf

CONSERJERÍA DE MEDIO AMBIENTE Y ORDENACIÓN DEL TERRITORIO: Comparador WMS Ortofotos. Canal Rediam. Junta de Andalucía. Disponible en http:// www.juntadeandalucia.es/medioambiente/site/rediam/menuitem.aedc2250f6db83cf8c a78ca731525ea0/?vgnextoid=eab1d61d8470f210VgnVCM2000000624e50aRCRD

CORTÉS PUYA, T. (2002): Recuperación del Patrimonio Cultural Urbano como Recurso Turístico: memoria para optar al grado de doctor (Miguel Ángel Troitiño Vinuesa, director.). Madrid, Universidad Complutense de Madrid.

DELGADO SILVA, R. (coord.) (2004): Estudio sobre potencialidades turísticas de las comarcas implicadas en la iniciativa comunitaria Equal Vía Verde para emprender. Campillos.

FERNÁNDEZ CACHO, S. (2008): Patrimonio Arqueológico y Planificación Territorial. Estrategias de Gestión Para Andalucía. Sevilla, Consejería de Cultura de la Junta de Andalucía y Universidad de Sevilla.

FERNÁNDEZ TABALES A. \& SANTOS PAVÓN E. (1999): «Turismo y patrimonio histórico en Andalucía: Magnitudes Generales y Estrategias de Planificación», Boletín de la A.G.E., no 28, pp. 119-134.

FERNÁNDEZ, G. \& GUZMÁN RAMOS, A. (2004): «El Patrimonio Histórico-Cultural revalorizado en el marco de un desarrollo sustentable del turismo», Perspectivas del Turismo Cultural II NAyA, Argentina. 
FORONDA ROBLES, C. (2002): «La intervención de los programas de desarrollo rural en el patrimonio natural andaluz». Ponencia presentada en el Coloquio Turismo y transformaciones urbanas en el siglo XXI, Almería, Universidad de Almería.

GALLARDO CASTILLO, M. J. (2013): Gestión y defensa del patrimonio público local. Granada, CEMCI.

GONZÁLEZ-VARAS IBÁÑEZ, I. (2014): Las ruinas de la memoria: Ideas y conceptos para una (im)posible teoría del patrimonio cultural. México D.F., Siglo XXI Editores.

GUERRERO MISA L.J., COBOS RODRÍGUEZ L.M., GUTIÉRREZ LÓPEZ J.M. \& GENER BALLASOTE J.M. (1998): «Informe: Ruta arqueológica de los Pueblos Blancos», Revista de arqueología, no 204, pp. 6-12.

HERNÁNDEZ RAMÍREZ, J. (2008): «Hiperespecialización turística y desactivación del patrimonio. La gestión eclesiástica del Patio de los Naranjos de la Catedral de Sevilla», en Hernández Ramírez, J. \& Díaz Brenis E. (coord.) Patrimonio cultural, turismo y religión. México, Escuela Nacional de Antropología e Historia.

HERNÁNDEZ RAMÍREZ, J. (2015): «Turismo de Base Local en la globalización», Revista Andaluza de Antropología, no 8, pp. 1-18.

HERNÁNDEZ RAMÍREZ, J. (2011): «Naturaleza a la carta. La retórica de la sostenibilidad turística y sus implicaciones en las políticas públicas en Andalucía», en Prats, Llorenç y Santana, Agustín (coord.) Turismo y patrimonio, entramados narrativos. El Sauzal, ACA y PASOS.

HERNÁNDEZ RAMÍREZ, J., \& GARCÍA VARGAS, E. (2013): Compartiendo el patrimonio: paisajes culturales y modelos de gestión en Andalucía y Piura. Sevilla, Universidad de Sevilla, Secretariado de Publicaciones.

LUHMANN, N. (2012): Theory of society. Volume I. Stanford, Calif: Stanford University Press.

MARCOS ARÉVALO, J. (2004): «La tradición, el patrimonio y la identidad», Revista de estudios extremeños, vol. 60, n 3, pp. 925-956.

MARTÍNEZ CARAZO, P.C. (2006): «El método de estudio de caso. Estrategia metodológica de la investigación científica», Pensamiento \& Gestión, n 20, pp. 165-193.

MARTÍNEZ YÁÑEZ, C. (2007): «Los nuevos planteamientos de la gestión del patrimonio cultural en el ámbito urbano: planes estratégicos y distritos culturales», Revista electrónica e-rph 1.

MERINO RODRÍGUEZ, R. \& ZAMORA ACOSTA, E. (2009): «La colaboración entre los actores turísticos en ciudades patrimoniales. Reflexiones para el análisis del desarrollo turístico», Revista de Turismo y Patrimonio Cultural, vol. 7, n 2, pp. 219-238.

MINISTERIO DE HACIENDA Y ADMINISTRACIONES PÚBLICAS: Sede Electrónica de Catastro. Disponible en http://www.sedecatastro.gob.es/

MORENO NAVARRO, A. (1983): «Olvera, Patrimonio Cultural y Arquitectónico», Revista Feria y Fiestas de San Agustín, nº 20, pp. 9-11.

NEIMAN, G. \& QUARANTA, G. (2006): «Los estudios de caso en la investigación sociológica», en VASILACHIS, I. (coord.) (2006) Estrategias de investigación cualitativa. Barcelona, Gedisa. 
OLIVEIRA, D., PASQUOTTO, M.A. \& MORALES, S. (2014): “Coordinación y estructuras de gobernanza en un sistema productivo de turismo", Estudios y perspectivas en turismo, vol. 23, $\mathrm{n}^{\mathrm{o}} 2$, pp. 343-361.

PÉREZ ORDÓÑEZ, A. (2011): «Arquitectura y urbanismo islámicos en la Sierra de Cádiz», Arqueología, Historia y Viajes sobre el Mundo Medieval, nº 41, pp. 50-59.

PRATS, L. \& SANTANA, A. (coords.) (2011): Turismo y Patrimonio, entramados narrativos. El Sauzal, ACA y PASOS.

RODRÍGUEZ PALMA, P. (1999): Olvera, historia fotográfica. Olvera, Excmo. Ayuntamiento de Olvera.

SUÁREZ JAPÓN, J.M. (1982): El hábitat rural de la Sierra de Cádiz. Cádiz, Diputación Provincial de Cádiz.

TROITIÑO TORRALBA, L. (2015): «La dimensión turística del patrimonio cultural de la ciudad de Lorca (Murcia, España)», Cuadernos de Turismo, n 36, pp. 389-414.

TROITIÑO VINUESA, M.Á. (2003): «La protección, recuperación y revitalización funcional de los centros históricos», en Horacio Capel (coord.) Ciudades, arquitectura y espacio urbano. Instituto de Estudios Socioeconómicos de Cajamar.

TROITIÑO VINUESA, M.Á. (coord.) (2009): Ciudades Patrimonio de la Humanidad: Patrimonio, turismo y recuperación urbana. Sevilla, Universidad Internacional de Andalucía.

VELASCO GONZÁLEZ, M. (2009): «Gestión turística del patrimonio cultural: enfoques para un desarrollo sostenible del turismo cultural», Cuadernos de Turismo, n²3, pp. 237-253.

YACUZZI, E. (2005): «El estudio de caso como metodología de investigación: teoría, mecanismos causales, validación», CEMA Working Papers: Serie Documentos de Trabajo. 296.

ZAMORA, E. (2011): «Sobre patrimonio y desarrollo. Aproximación al concepto de patrimonio cultural y su utilización en procesos de desarrollo territorial», Revista de Turismo y Patrimonio Cultural, vol. 9, n 1, pp. 101-113. 


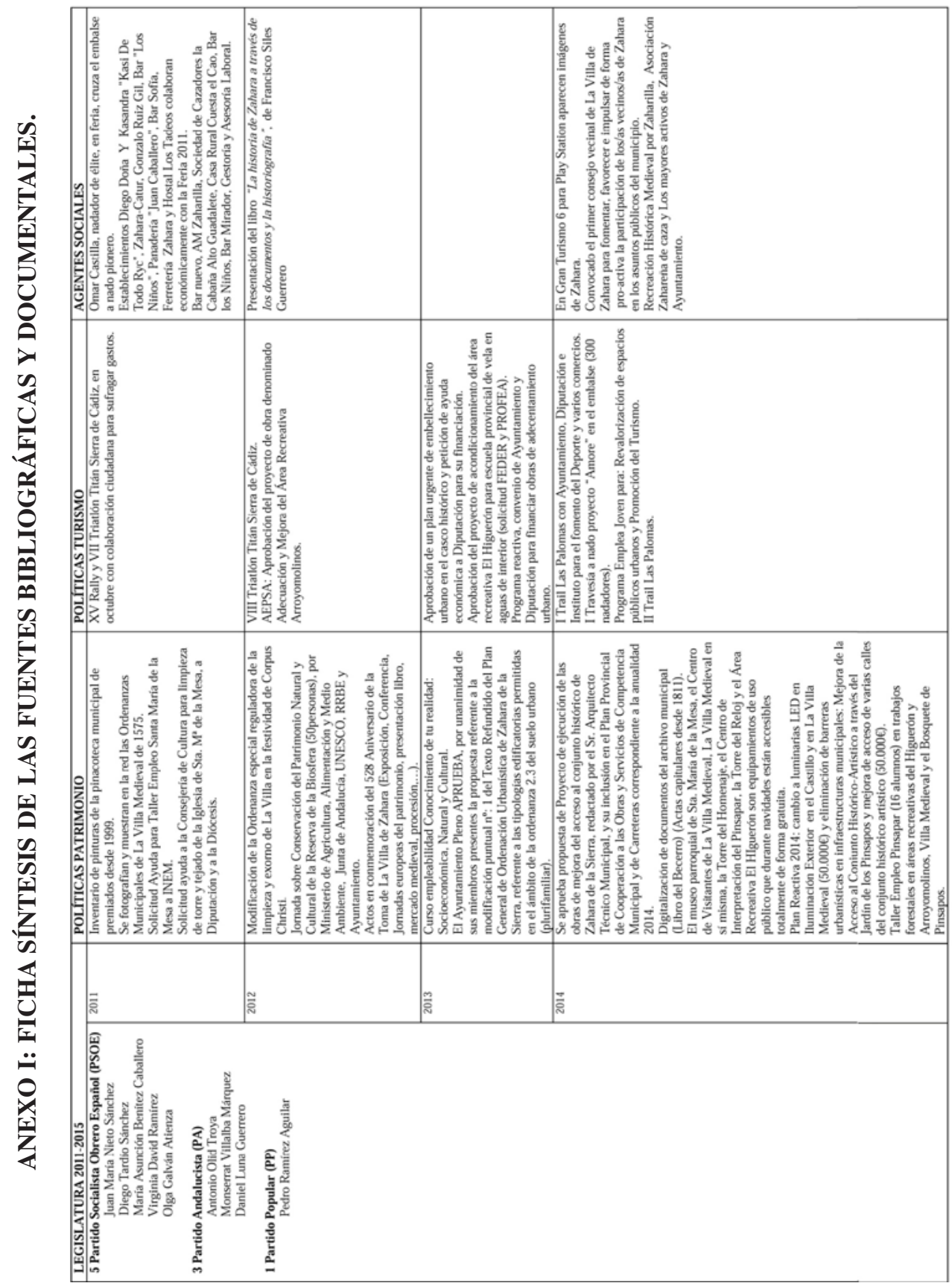


